\title{
Estrutura do componente arbóreo em Floresta Ombrófila Densa Montana no Parque Natural Municipal Nascentes de Paranapiacaba (PNMNP), Santo André, SP, Brasil ${ }^{1}$
}

\author{
Marcos Enoque Leite Lima, ${ }^{2,5}$, Inês Cordeiro ${ }^{3}$ e Paulo Roberto H. Moreno ${ }^{4}$ \\ Recebido: 26.05.2010; aceito: 3.02.2011
}

\begin{abstract}
Structure of the tree component in montane tropical rain forest in the Parque Natural Municipal Nascentes de Paranapiacaba (PNMNP), Santo André, São Paulo State, Brazil). It was performed a phytosociological analysis of two 0.5 hectare plots (P1 and P2) of tropical montane rain forest in the PNMNP. Trees with DBH (diameter at breast height) of $4.8 \mathrm{~cm}$ or more were sampled, a total of 1,992 individuals belonging to 183 species, 103 genera and 49 families. Most of the species are zoochoric and the number of pioneer and non-pioneer individuals is similar in the two plots. The Myrtaceae family was the richest in species number, followed by Rubiaceae, Lauraceae and Melastomataceae. The specific diversity was obtained by the Shannon's Index (H'), 3.779 in P1 and 4.049 in P2 and the equability by Pielou's Index (J), 0.770 in P1 and 0.836 in P2. The diversity indexes found in PNMNP are similar to those ones found in other protected areas in the State of São Paulo and may indicate that the air pollutants produced by the industrial complex of Cubatão were not so deleterious as in other surrounding areas in the Mogi river valey and Reserva Biológica do Alto da Serra de Paranapiacaba. Furthermore, the presence of big trees belonging to non-pioneer species in P2 indicates that PNMNP may keep relicts of the original forest that covered the area in the past.
\end{abstract}

Key words: dispersal syndromes, diversity, floristics, phytosociology, successional categories

RESUMO - (Estrutura do componente arbóreo em Floresta Ombrófila Densa Montana no Parque Natural Municipal Nascentes de Paranapiacaba (PNMNP), Santo André, SP, Brasil). Foi realizada a análise fitossociológica de duas parcelas (P1 e P2) de 0,5 hectare em Floresta Ombrófila Densa Montana do PNMNP. Foram amostradas as árvores com DAP (diâmetro a 1,30 m de altura do solo) $\geq 4,8 \mathrm{~cm}$, num total de 1.992 indivíduos, distribuídos em 183 espécies, 103 gêneros e 49 famílias, sendo a maioria delas zoocórica, com uma distribuição equilibrada de indivíduos pioneiros e não pioneiros em P1 e P2. A família Myrtaceae foi a mais rica em espécies, seguida de Rubiaceae, Lauraceae e Melastomataceae. A diversidade específica foi obtida através do Índice de Shannon (H'), sendo 3,779 em P1 e 4,049 em P2 e a equabilidade pelo Índice de Pielou (J), sendo 0,770 em P1 e 0,836 em P2. Os índices de diversidade encontrados no PNMNP são semelhantes aos de outras Unidades de Conservação do Estado de São Paulo, uma indicativa de que os poluentes atmosféricos produzidos pelo complexo industrial de Cubatão certamente não foram aí tão prejudiciais quanto para áreas próximas localizadas no vale do rio Mogi e Reserva Biológica do Alto da Serra de Paranapiacaba. Além disso, a presença de árvores de grande porte pertencentes a espécies não pioneiras na P2 indica que o PNMNP pode ainda manter relictos da floresta original que recobria a região no passado. Palavras-chave: categorias sucessionais, diversidade, fitossociologia, florística, síndromes de dispersão

\section{Introdução}

As florestas tropicais em todo mundo estão sujeitas a perturbações que alteram sua estrutura, seja por fatores geomorfológicos, climáticos ou bióticos, incluindo-se, entre os últimos, aqueles de origem antrópica (ACIESP 1997, Creed 2006). Essas perturbações promoverão a sucessão secundária da

1. Parte da Dissertação de Mestrado do primeiro autor

2. Curso de Pós-Graduação em Biodiversidade Vegetal e Meio Ambiente do Instituto de Botânica de São Paulo

3. Instituto de Botânica, Av. Miguel Estéfano 3687, Caixa Postal 68041, 04301-902 São Paulo, SP, Brasil

4. Universidade de São Paulo, Instituto de Química, Departamento de Química Fundamental, Av. Prof. Lineu Prestes, 748, bloco 11, térreo, Cidade Universitária, 05508-000 São Paulo, SP, Brasil

5. Autor para correspondência: marcosenoque@gmail.com 
floresta (Burslem \& Swaine 2002) e, dependendo de sua magnitude e da vegetação limítrofe, é que serão conduzidas as etapas iniciais e o estabelecimento do processo sucessional (Porto et al. 2008), bem como a regeneração de sua diversidade florística (Solórzano et al. 2005).

A composição das espécies arbóreas dominantes de uma floresta tropical modifica-se constantemente, tanto no espaço quanto no tempo (Aubreville 1938). Essa modificação acompanha o ciclo de crescimento da floresta que consiste na abertura do dossel, construção e maturidade, resultando num mosaico de manchas em diferentes fases de crescimento que são responsáveis pela manutenção da floresta ao longo do tempo (Whitmore 1990).

A ocorrência de espécies de diferentes grupos sucessionais é uma característica comum às florestas tropicais (Whitmore 1978, 1982) e sua freqüência pode indicar o estado sucessional geral da floresta (Budowski 1965). Os mosaicos florestais podem ser avaliados através das características ecofisiológicas de suas espécies arbóreas, que determinam sua classificação em grupos sucessionais (Budowski 1965, Whitmore 1989), das características arquiteturais de suas árvores (Oldeman 1983, Torquebiau 1986) ou com base na composição florística e/ou parâmetros quantitativos de suas espécies (Fonseca \& Rodrigues 2000, Richards 1952, Watt 1947, Whitmore 1975).

Entre os sistemas de classificação das espécies em grupos ecológicos, encontra-se o de Budowski (1965) com quatro categorias (pioneiras, secundárias iniciais, secundárias tardias e espécies climácicas) e o de Swaine \& Whitmore (1988) com apenas duas categorias (pioneiras e não pioneiras). Assim, não há um padrão claramente estabelecido para florestas tropicais relativo à freqüência dos grupos ecológicos na avaliação do estádio sucessional geral da floresta.

Muitos estudos fitossociológicos têm sido realizados em diferentes formações florestais na tentativa de comparar fragmentos sob diferentes condições edáficas e sucessionais (Felfili \& Fagg 2007, Meireles et al. 2008, Melo et al. 2000, Silva et al. 2009, Silva et al. 2008, Siqueira et al. 2009, Sugiyama et al. 2009). Poucos trabalhos avaliam trechos perturbados ou variações do mosaico florestal em um mesmo remanescente (Fonseca \& Rodrigues 2000, Gandolfi et al. 1995).

A estrutura de florestas tropicais secundárias é mais simples se comparada com a de florestas maduras, pois apresenta algumas características típicas como alta densidade total, baixa área basal, árvores com altura e diâmetro menores e consequentemente baixo volume de madeira, independentemente do tamanho do fragmento (Brown \& Lugo 1990). Além disso, a riqueza e a biomassa das florestas secundárias custam a recuperar-se, mesmo quando o impacto que as originaram ocorreu há vários anos (Chazdon 2008).

As florestas secundárias encontradas atualmente na região de Paranapiacaba são resultantes da intensa derrubada de árvores da floresta original, ocorrida a partir da década de 1860 , em virtude da implantação e manutenção da ferrovia Santos-Jundiaí e da própria Vila de Paranapiacaba, além do impacto da poluição atmosférica produzida pelo complexo industrial (indústrias químicas, petroquímicas, siderúrgicas e de fertilizantes) de Cubatão, entre as décadas de 1950 até 1980, afetando diretamente a estrutura de alguns trechos destas florestas (JICA 1990, Pompéia 2006).

Com o objetivo de verificar se a poluição atmosférica do complexo industrial de Cubatão teria afetado de alguma forma a vegetação do Parque Natural Municipal Nascentes de Paranapiacaba (PNMNP), foi avaliado o componente arbóreo de 1 ha de floresta secundária, visando contribuir para o conhecimento do estado atual de conservação das florestas nesta região.

\section{Material e métodos}

Área de estudo - O PNMNP localiza-se a $23^{\circ} 46^{\prime} 41^{\prime \prime} S$ e $46^{\circ} 18^{\prime} 16^{\prime \prime} \mathrm{W}$, com altitudes que variam de 780 a $1.174 \mathrm{~m}$, e área total de aproximadamente 400 ha. O Parque localiza-se em uma área de proteção de mananciais no Município de Santo André, São Paulo, Brasil, onde encontram-se as nascentes do rio Grande, o maior rio formador da represa Billings, responsável pelo abastecimento de 1,5 milhões de pessoas nos municípios da Grande São Paulo (PMSA 2008). A criação desta Unidade de Conservação (UC) em junho de 2003, teve o intuito principal de conservar os contrafortes da Serra do Mar e as nascentes formadoras do rio Grande, além de contribuir para a valorização do patrimônio histórico nacional da Vila de Paranapiacaba (PMSA 2005), apesar da mesma não estar incluída na área do Parque. Vale ressaltar que o PNMNP não é um fragmento isolado de Mata Atlântica, mas uma área de preservação limítrofe ao Parque Estadual da Serra do Mar - Núcleo Cubatão, além de estar muito próximo da Reserva Biológica do Alto da Serra de Paranapiacaba (RB) (figura 1). 


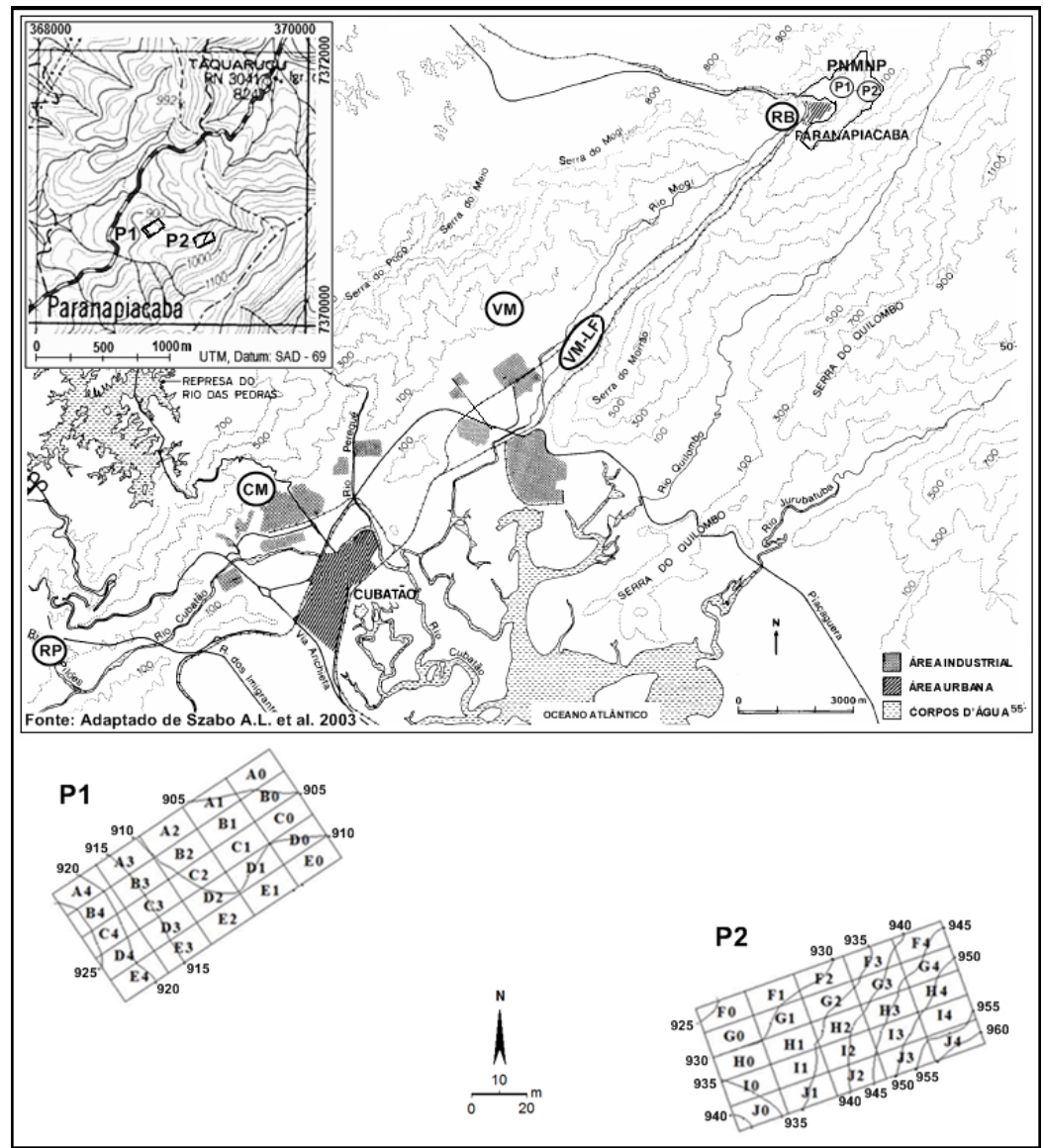

Figura 1. Localização do Parque Natural Municipal Nascentes de Pararanapiacaba (PNMNP), Santo André, SP, Brasil, com detalhe da topografia e localização das parcelas P1 e P2. RB: Reserva Biológica do Alto da Serra de Paranapiacaba incluindo as áreas RB-AB, RB-AR e RB-CN (Sugiyama 2009); VM-LF: vale do rio Mogi (Leitão Filho 1993); VM: vale do rio Mogi e CM: Caminho do Mar (Pompéia 1997); VP: vale do rio Pilões incluindo as parcelas RP-LF1, RP-LF2 e RP-LF3 (Leitão Filho 1993) e a parcela RP-Pomp (Pompéia1997). Abaixo do mapa estão representadas as parcelas P1 e P2, com detalhe topográfico, orientadas segundo sua localização na área.

Figure 1. Localization of the "Parque Natural Municipal Nascentes de Paranapiacaba" (PNMNP) Santo André, SP, Brazil, with detail of the topography and location of the plots de P1 e P2. RB: Biological Reserve Alto da Serra de Paranapiacaba included areas RB-AB, RBAR and RB-CN (Sugiyama 2009); VM-LF: valey of river Mogi (Leitão Filho 1993); VM valey of river Mogi and CM: Caminho do Mar (Pompéia 1997); VP: valey of river Pilões included the plots RP-LF1, RP-LF2 e RP-LF3 (Leitão Filho 1993) and the plot RP-Pomp (Pompéia 1997). Below the map are represented the P1 and P2 plots, with their topographic details and orientation accordingly their actual position in the area.

A área do PNMNP apresenta embasamento geológico cristalino, resultando em relevo bastante acidentado, com altas e médias declividades e amplitudes topográficas superiores a 200 metros, com escarpas festonadas, espigões digitados, morrotes baixos, morros paralelos e a falha de Cubatão (PMSA 2008). O Parque localiza-se no Planalto Paulistano e pertence à Província Geomorfológica do Planalto Atlântico e ao Complexo Litológico Costeiro. Apresenta na sua porção SE um perfil retilíneo com diversas nascentes e grotas, solos rasos, com grandes matacões, vales fechados e abruptos, com topos de morro estreitos e alongados. Esses aspectos geomorfológicos, associados à chuva abundante, tornam os deslizamentos muito frequentes na região do parque (PMSA 2008).

O clima da região é classificado como Cfa, ou seja, clima tropical com ausência de estação seca e verão quente (Köppen 1948). Dados relativos ao período de janeiro a dezembro de 2005 e janeiro a dezembro de 2006, fornecidos pela empresa Solvay instalada na região, revelam pluviosidade anual de $1796,7 \mathrm{~mm}$ para 2005 e $1869,3 \mathrm{~mm}$ para 2006 , com média mensal máxima de $22,5^{\circ} \mathrm{C}$ em 2005 e $22,7^{\circ} \mathrm{C}$ em 2006. As temperaturas médias mensais mínimas foram atingidas no inverno com $14,9{ }^{\circ} \mathrm{C}$ e $14,7{ }^{\circ} \mathrm{C}$ para 2005 e 2006 , respectivamente e as médias da umidade relativa do ar para os anos de 2005 e 2006 
foram 93 e 93,6\%, respectivamente.

Em condições climáticas normais, observa-se que em Cubatão, no final do período noturno e pela manhã, os ventos sopram na direção do oceano (S e SW), enquanto que no período mais quente do dia, ocorre a inversão na direção dos ventos, que passam a soprar para a serra $(\mathrm{N}$ e $\mathrm{NW})$, transportando umidade e poluentes do complexo industrial diretamente para as escarpas, provocando sua concentração nos vales dos rios Mogi, Perequê e Caminho do Mar (JICA 1990, Pompéia 1997).

Uma outra particularidade dessa região, em relação às correntes de circulação atmosférica, é que elas favorecem a ocorrência das chamadas chuvas de encosta, fato que explica a alta pluviosidade, além disso, o relevo associado a estas correntes promove a formação da neblina observada constantemente na região (PMSA 2008).

A região do PNMNP é recoberta pela Floresta Ombrófila Densa Montana, secundária em boa parte de sua extensão, mas relativamente conservada em alguns trechos, particularmente aqueles menos afetados pela poluição gerada no complexo industrial de Cubatão, nas nascentes dos rios Grande e Pequeno (PMSA 2008, Veloso et al. 1991). O trecho de floresta localizado nos limites do Parque não apresenta características de uma floresta madura ou climácica, pois no passado sofreu intenso extrativismo de madeira utilizada para instalação e manutenção da ferrovia, bem como combustível para mover as caldeiras das locomotivas que transportavam o café até o porto de Santos. Área amostral - Para caracterização da estrutura foram escolhidos dois trechos de um continuum florestal localizados ao longo da Trilha da Comunidade, no percurso entre a Cachoeira da Água Fria e a Comunidade, nas cabeceiras do rio Grande.

A avaliação fitossociológica foi realizada através do método de parcelas (Mueller-Dombois \& Ellenberg 1974). A área total amostrada foi de 1 hectare, porém, a ausência de uma área contínua nessas dimensões, sem a presença de grandes moitas de bambus e áreas desmatadas no mesmo "continuum", impediu a implantação de uma parcela única. Assim, duas parcelas permanentes (denominadas P1 e P2) de $50 \times 100 \mathrm{~m}$ distantes 200 metros entre si, foram implantadas e geo-referenciadas, sendo cada uma delas subdividida em 25 subparcelas de $10 \times 20 \mathrm{~m}$ (figura 1).

A parcela P1 localiza-se a $23^{\circ} 46^{\prime} 08^{\prime \prime} \mathrm{S}$ e $46^{\circ} 17^{\prime} 09^{\prime \prime} \mathrm{W}$ e possui borda perturbada na extremidade sudoeste, compreendendo as sub-parcelas A4, B4, C4,
D4 e E4, que segundo relato dos moradores, foi utilizada como pastagem até a década de 1970 . A parcela P2 localiza-se a $23^{\circ} 46^{\prime} 10^{\prime \prime} \mathrm{S}$ e $46^{\circ} 17^{\prime} 00^{\prime \prime} \mathrm{W}$ por outro lado, não apresenta perturbação antrópica muito evidente. Em relação à topografia, a parcela P1 encontra-se em terreno com altitudes que variam no sentido nordeste - sudoeste de 903 a $927 \mathrm{~m}$, portanto $24 \mathrm{~m}$ de desnível, enquanto que em P2 a altitude varia de 923,08 a $964,35 \mathrm{~m}$ no sentido oeste-leste, portanto com desnível de $40 \mathrm{~m}$ (figura 1).

Coleta de dados - Os trabalhos de campo ocorreram em diferentes períodos. No período de setembro de 2005 a julho de 2006, foram alocadas as parcelas, medidos e demarcados com placas de metal numeradas, todos os indivíduos arbóreos, samambaia-açus e palmeiras com diâmetro a $1,30 \mathrm{~m}$ a altura do solo (DAP) igual ou superior a $4,8 \mathrm{~cm}$. A altura das árvores foi estimada com auxílio de tesoura de poda alta (10 m). Os indivíduos mortos em pé e as lianas com DAP igual ou superior a $4,8 \mathrm{~cm}$ também foram amostrados e medidos, mas não incluídos nos cálculos dos parâmetros fitossociológicos. A coleta parcial dos espécimes foi iniciada entre 2006 e 2007, sendo concluída no período de janeiro de 2008 a novembro de 2009. Os espécimes coletados foram processados de acordo com as técnicas descritas para coleta de material vegetal (Fidalgo \& Bononi 1989). Para cada uma das espécies encontradas na área foi depositado um material testemunho no Herbário do Instituto de Botânica de São Paulo (SP).

As identificações foram feitas com auxílio da literatura específica, consultas a especialistas das famílias Asteraceae (Rosângela Simão-Bianchini - IBt), Cyatheaceae (Pedro Bond Schwartsburd - IBt), Euphorbiaceae, Phyllanthaceae (Inês Cordeiro - IBt), Lauraceae (Sueli Antonia Nicolau - IBt), Malpighiaceae (Maria Candida Mamede - IBt), Moraceae (Sérgio Romaniuc Neto - IBt), Myrtaceae (Marcos Sobral - UFMG), Thymelaeaceae (Lúcia Rossi - IBt) e comparações com o acervo do Herbário Científico do Estado "Maria Eneyda P. Kauffmann Fidalgo" (SP) do Instituto de Botânica. As espécies foram ordenadas por famílias segundo o sistema proposto pelo Angiosperm Phylogeny Group (APG III 2009). Para classificação das Cyateaceae foi utilizada a revisão de Cyatheaceae para o Sul e Sudeste do Brasil (Fernandes 1997). Para conferência do nome das espécies foi utilizada a base de dados do site W3tropicos do Missouri Botanical Garden, disponível on line (http://www.tropicos.org/). 
Análise dos dados - A diversidade de espécies foi medida pelo índice de Shannon (H'), calculado com base no logaritmo natural, e a equabilidade pelo índice de Pielou (J') (Felfili \& Rezende 2003, Martins 1991, Mueller-Dombois \& Ellenberg 1974, Pielou 1975).

A classificação das espécies segundo a síndrome de dispersão foi realizada de acordo com os critérios estabelecidos por van der Pijl (1972), com base nas características dos frutos e sementes. Foram calculadas as médias e o desvio padrão do número e porcentagem de indivíduos, de acordo com a síndrome de dispersão, para cada parcela.

Para reduzir eventuais erros de classificação sucessional das espécies, optou-se por um agrupamento mais simples, com apenas duas grandes categorias sucessionais: as pioneiras "lato sensu", incluindo as pioneiras e secundárias iniciais; e as não pioneiras, que são as tardias "lato sensu" incluindo-se neste grupo as espécies secundárias tardias e as umbrófilas (Catharino et al. 2006, Whitmore 1989). Ao final também foram calculadas as médias e o desvio padrão do número e porcentagem de indivíduos nas respectivas categorias sucessionais de cada parcela.

A estrutura da vegetação foi descrita com base nos histogramas das distribuições de frequências nas classes de diâmetro e de altura, cuja amplitude de intervalos foi obtida através do procedimento sugerido por Spiegel (1976). Os parâmetros fitossociológicos utilizados para espécies foram frequência (FR), densidade (DR) e dominância (DoR) relativas, além dos índices do valor de importância (VI) e valor de cobertura (VC) (Mueller-Dombois \& Ellenberg 1974). Para os cálculos foi utilizado o programa FITOPAC (Shepherd 2006).

A similaridade floristica entre o PNMNP e outras áreas da Serra do Mar sob influência das emissões do complexo industrial de Cubatão (Leitão Filho 1993, Pompéia 1997, Sugiyama et al. 2009) foi avaliada por análise de agrupamento. Para a construção da matriz de similaridade foi utilizada a distância euclidiana, calculada a partir dos dados de uma matriz de abundância das espécies com mais de um indivíduo, transformada pela raiz quadrada, sendo o dendrograma construído através do método da distância média (UPGMA) (Mueller-Dombois \& Ellenberg 1974).

\section{Resultados}

Análise florística - Na parcela P1, 1.237 indivíduos foram amostrados, pertencentes a 128 espécies de 39 famílias; na parcela P2 foram amostrados 755 indivíduos de 127 espécies e 37 famílias (tabela 1).

Myrtaceae foi a família com maior riqueza tanto na parcela P1 como em P2. Asteraceae, Melastomataceae e Nyctaginaceae apresentaram o maior número de indivíduos em P1; já em P2, Cyatheaceae e Lauraceae foram as mais numerosas. Algumas famílias ocorreram apenas em uma das parcelas, como é o caso de Chloranthaceae e Clethraceae em P1 e Sapotaceae e Malvaceae em P2 (figura 2).

Em relação aos gêneros com maior número de espécies, na parcela P1 Myrcia apareceu com oito espécies, seguido de Ocotea (7 spp.), Eugenia (6 spp.), Rapanea e Miconia, com cinco espécies cada. Na parcela P2 apareceram os gêneros Eugenia (10 spp.), Ocotea (8 spp.) e Myrcia (6 spp.) (tabela 1).

Do total de espécies amostradas, Guapira opposita (158 ind) e Psychotria suterella (130 ind) foram as mais abundantes em P1 (tabela 2) e Bathysa stipulata (97 ind) e Cyathea delgadii (48 ind) em P2 (tabela 3).

Diversidade e equabilidade - A diversidade total encontrada no presente estudo foi 4,20 (H'), sendo entretanto maior em P2 $\left(\mathrm{H}^{\prime}=4,01\right)$ do que em P1 $\left(\mathrm{H}^{\prime}=3,80\right)$. Quanto à equabilidade $\left(\mathrm{J}^{\prime}\right)$, o valor total $(\mathrm{P} 1$ + P2) foi 0,81, sendo em P1 0,77 e em P2 0,84. Aspectos da estrutura arbórea - A avaliação da estrutura arbórea da parcela P1 revelou que Miconia сависи е Guapira opposita apresentam os maiores VI e VC. Estes valores devem-se principalmente ao maior valor de DoR para $M$. саbucu enquanto que para G. opposita, a FR e DR foram os descritores que contribuíram para o maior VI. Outras espécies como Psychotria suterella, Tibouchina pulchra e Croton macrobothrys também apareceram entre aquelas com maiores VIs em P1 (tabela 2).

Em relação à estrutura da parcela $\mathrm{P} 2$, as espécies que apresentaram os maiores valores de VI foram Bathysa stipulata, com valores de DR e FR superiores aos de todas as outras espécies e Alchornea triplinervea, em função da maior DoR. Estas mesmas espécies apresentam os maiores VC. Outras espécies como Cyathea delgadii e Guapira opposita também apresentam altos valores para VI e VC (tabela 3).

Categorias sucessionais - Em relação à categoria sucessional, não houve diferença significativa na média da porcentagem do número de indivíduos pioneiros $(\mathrm{P})$ entre as parcelas $(40,99 \pm 9,16 \%)$ e $\mathrm{P} 2$ $(36,46 \pm 4,46 \%)$, e não pioneiros (NP), P1 (47,05 \pm 
Tabela 1. Espécies arbóreas encontradas nas 2 parcelas de 0,5 hectare (P1 e P2) do Parque Natural Municipal Nascentes de Paranapiacaba, Santo André, SP, Brasil. P: espécies pioneiras; NP: não pioneiras; NC: espécie não caracterizada.

Table 1. Tree species recorded in two 0.5 hectare plots (P1 and P2) in the Parque Natural Municipal nascentes de Paranapiacaba, Santo André, SP, Brazil. P: pioneer species; NP: non-pioneer species; NC: not characterized species.

\begin{tabular}{|c|c|c|c|c|c|}
\hline \multirow[t]{2}{*}{ Família/Espécie } & \multirow[t]{2}{*}{ Número de coletor } & \multicolumn{2}{|c|}{ Parcelas } & \multirow{2}{*}{$\begin{array}{l}\text { Categegorias } \\
\text { sucessionais }\end{array}$} & \multirow{2}{*}{$\begin{array}{l}\text { Síndrome de } \\
\text { dispersão }\end{array}$} \\
\hline & & $\mathrm{P} 1$ & $\mathrm{P} 2$ & & \\
\hline \multicolumn{6}{|l|}{ ANNONACEAE } \\
\hline Guatteria elliptica R.E. Fr. & Lima 1709 & $\mathrm{x}$ & $\mathrm{x}$ & $\mathrm{P}$ & Zoocórica \\
\hline Guatteria polycarpa R.E. Fr. & Lima 2010 & $\mathrm{x}$ & - & $\mathrm{P}$ & Zoocórica \\
\hline Annona neocericea $\mathrm{H}$. Rainer & Lima 1720 & $\mathrm{x}$ & $\mathrm{x}$ & $\mathrm{P}$ & Zoocórica \\
\hline Xylopia langsdorfiana A. St.-Hil. \& Tulasne & - & - & $\mathrm{x}$ & $\mathrm{P}$ & Zoocórica \\
\hline \multicolumn{6}{|l|}{ APOCYNACEAE } \\
\hline Aspidosperma olivaceum Müll. Arg. & Lima 1880 & $\mathrm{x}$ & $\mathrm{x}$ & NP & Anemocórica \\
\hline \multicolumn{6}{|l|}{ ARALIACEAE } \\
\hline Dendropanax heterophyllus (Marchal) Frodin & Lima 1413 & - & $\mathrm{x}$ & $\mathrm{P}$ & Zoocórica \\
\hline Schefflera angustissima (Marchal) Frodin & Lima 2254 & $\mathrm{x}$ & $\mathrm{x}$ & $\mathrm{P}$ & Zoocórica \\
\hline \multicolumn{6}{|l|}{ ARECACEAE } \\
\hline Bactris setosa Mart. & Lima 2293 & $\mathrm{x}$ & $\mathrm{x}$ & NP & Zoocórica \\
\hline Euterpe edulis Mart. & - & - & $\mathrm{x}$ & NP & Zoocórica \\
\hline \multicolumn{6}{|l|}{ ASTERACEAE } \\
\hline Baccharis oreophila Malme & Lima 1989 & $\mathrm{x}$ & - & $\mathrm{P}$ & Anemocórica \\
\hline Critoniopsis quinqueflora (Less.) H. Rob. & Lima 1000 & $\mathrm{x}$ & $\mathrm{x}$ & $\mathrm{P}$ & Anemocórica \\
\hline Piptocarpha axillaris (Less.) Baker & Lima 2250 & $\mathrm{x}$ & - & $\mathrm{P}$ & Anemocórica \\
\hline Vernonanthura divaricata (Spreng.) H. Rob. & Lima 1870 & $\mathrm{x}$ & - & $\mathrm{P}$ & Anemocórica \\
\hline Vernonanthura puberula (Less.) H. Rob. & Lima 2255 & $\mathrm{x}$ & $\mathrm{x}$ & $\mathrm{P}$ & Anemocórica \\
\hline \multicolumn{6}{|l|}{ BIGNONIACEAE } \\
\hline Jacaranda puberula Cham. & Lima 2257 & $\mathrm{x}$ & - & $\mathrm{P}$ & Anemocórica \\
\hline \multicolumn{6}{|l|}{ BORAGINACEAE } \\
\hline Cordia sellowiana Cham. & Lima 2169 & $\mathrm{x}$ & $\mathrm{x}$ & $\mathrm{NP}$ & Zoocórica \\
\hline Cordia trichoclada DC. & Lima 2322 & $\mathrm{x}$ & $\mathrm{x}$ & $\mathrm{P}$ & Zoocórica \\
\hline \multicolumn{6}{|l|}{ BURSERACEAE } \\
\hline Protium heptaphyllum (Aubl.) Marchand & Lima 1863 & $\mathrm{x}$ & - & NP & Zoocórica \\
\hline \multicolumn{6}{|l|}{ CELASTRACEAE } \\
\hline Maytenus robusta Reissek & Lima 2020 & $\mathrm{x}$ & - & NP & Zoocórica \\
\hline Salacia grandifolia (Mart.) G. Don & Lima 1672 & $\mathrm{x}$ & $\mathrm{x}$ & NP & Zoocórica \\
\hline \multicolumn{6}{|l|}{ CHLORANTHACEAE } \\
\hline Hedyosmum brasiliense Mart. ex Miq. & Lima 1176 & $\mathrm{x}$ & - & $\mathrm{P}$ & Zoocórica \\
\hline \multicolumn{6}{|l|}{ CLETHRACEAE } \\
\hline Clethra scabra Pers. & Lima 1569 & $\mathrm{x}$ & - & $\mathrm{P}$ & Anemocórica \\
\hline \multicolumn{6}{|l|}{ CLUSIACEAE } \\
\hline Clusia criuva Cambess. & Lima 1554 & $\mathrm{x}$ & - & $\mathrm{P}$ & Zoocórica \\
\hline \multicolumn{6}{|l|}{ CYATHEACEAE } \\
\hline Alsophila setosa Kaulf. & - & - & $\mathrm{x}$ & NP & Anemocórica \\
\hline Alsophila sternbergii (Sternb.) D.S. Conant & Lima 1985 & - & $\mathrm{x}$ & NP & Anemocórica \\
\hline \multicolumn{6}{|l|}{ CYATHEACEAE } \\
\hline Cyathea atrovirens (Langsd. \& Fisch.) Domin & - & $\mathrm{x}$ & - & $\mathrm{P}$ & Anemocórica \\
\hline Cyathea delgadii Sternb. & Lima 1278 & $\mathrm{x}$ & $\mathrm{x}$ & NP & Anemocórica \\
\hline Cyathea dichromatolepis (Fée) Domin & Lima 2340 & - & $\mathrm{x}$ & NP & Anemocórica \\
\hline Cyathea phalerata Mart. & Lima 1279 & $\mathrm{x}$ & $\mathrm{x}$ & NP & Anemocórica \\
\hline \multicolumn{6}{|l|}{ ELAEOCARPACEAE } \\
\hline Sloanea monosperma Vell. & Lima 1451 & - & $\mathrm{x}$ & NP & Anemocórica \\
\hline ERYTHROXYLACEAE & & & & & \\
\hline Erythroxylum cuspidifolium Mart. & Lima 1625 & $\mathrm{x}$ & $\mathrm{x}$ & NP & Zoocórica \\
\hline Erythroxylum gonoclados (Mart.) O.E. Schulz & Lima 1458 & $\mathrm{x}$ & - & NP & Zoocórica \\
\hline EUPHORBIACEAE & & & & & \\
\hline Alchornea glandulosa Poepp. & Lima 2068 & $\mathrm{x}$ & - & $\mathrm{P}$ & Zoocórica \\
\hline
\end{tabular}


Tabela 1 (continuação)

\begin{tabular}{|c|c|c|c|c|c|}
\hline \multirow[t]{2}{*}{ Família/Espécie } & \multirow[t]{2}{*}{ Número de coletor } & \multicolumn{2}{|c|}{ Parcelas } & \multirow{2}{*}{$\begin{array}{l}\text { Categegorias } \\
\text { sucessionais }\end{array}$} & \multirow{2}{*}{$\begin{array}{c}\text { Síndrome de } \\
\text { dispersão }\end{array}$} \\
\hline & & $\mathrm{P} 1$ & $\mathrm{P} 2$ & & \\
\hline Alchornea sidifolia Müll. Arg. & Lima 1522 & $\mathrm{x}$ & - & $\mathrm{P}$ & Zoocórica \\
\hline Alchornea triplinervia (Spreng.) Müll. Arg. & Lima 2105 & $\mathrm{x}$ & $\mathrm{x}$ & $\mathrm{P}$ & Zoocórica \\
\hline Croton macrobothrys Baill. & Lima 2100 & $\mathrm{x}$ & $\mathrm{x}$ & $\mathrm{P}$ & Zoocórica \\
\hline Pera glabrata (Schott) Poepp. ex Baill. & Lima 2063 & $\mathrm{x}$ & - & $\mathrm{P}$ & Zoocórica \\
\hline Sapium glandulosum (L.) Morong & Lima 2219 & $\mathrm{x}$ & $\mathrm{x}$ & $\mathrm{P}$ & Zoocórica \\
\hline \multicolumn{6}{|l|}{ FABACEAE } \\
\hline Andira fraxinifolia Benth. & Lima 2115 & - & $\mathrm{x}$ & NP & Zoocórica \\
\hline Inga sessilis (Vell.) Mart. & Lima 1796 & $\mathrm{x}$ & $\mathrm{x}$ & $\mathrm{P}$ & Zoocórica \\
\hline Piptadenia paniculata Benth. & Lima 1970 & $\mathrm{X}$ & $\mathrm{X}$ & $\mathrm{P}$ & Anemocórica \\
\hline Sclerolobium denudatum Vogel & Lima 1511 & $\mathrm{x}$ & - & NP & Anemocórica \\
\hline Senna multijuga (Rich.) H.S. Irwin \& Barneby & Lima 1790 & $\mathrm{x}$ & $\mathrm{x}$ & $\mathrm{P}$ & Zoocórica \\
\hline Zollernia ilicifolia (Brongn.) Vogel & Lima 2265 & - & $\mathrm{x}$ & NP & Zoocórica \\
\hline \multicolumn{6}{|l|}{ HUMIRIACEAE } \\
\hline Humiriastrum glaziovii (Urb.) Cuatrec. & Lima 2246 & $\mathrm{x}$ & - & NP & Zoocórica \\
\hline \multicolumn{6}{|l|}{ ICACINACEAE } \\
\hline Citronella paniculata (Mart.) R.A. Howard & Lima 1432 & - & $\mathrm{X}$ & NP & Zoocórica \\
\hline \multicolumn{6}{|l|}{ LAURACEAE } \\
\hline Cinnamomum glaziovii (Mez) Kosterm. & Lima 2084 & $\mathrm{x}$ & $\mathrm{x}$ & NP & Zoocórica \\
\hline Cryptocarya aschersoniana $\mathrm{Mez}$ & Lima 2224 & - & $\mathrm{x}$ & NP & Zoocórica \\
\hline Cryptocarya moschata Nees \& Mart. & Lima 2315 & - & $\mathrm{x}$ & NP & Zoocórica \\
\hline Cryptocarya saligna $\mathrm{Mez}$ & Lima 2231 & $\mathrm{x}$ & $\mathrm{x}$ & NP & Zoocórica \\
\hline Licaria cf. armeniaca (Nees) Kosterm. & Lima 2037 & $\mathrm{x}$ & - & NP & Zoocórica \\
\hline Ocotea bicolor Vattimo & Lima 1959 & $\mathrm{x}$ & - & NP & Zoocórica \\
\hline Ocotea brachybotrya (Meisn.) Mez & Lima 2290 & - & $\mathrm{x}$ & NP & Zoocórica \\
\hline Ocotea diospyrifolia (Meisn.) Mez & Lima 1593 & - & $\mathrm{x}$ & NP & Zoocórica \\
\hline Ocotea dispersa (Ness) Mez. & Lima 2052 & $\mathrm{X}$ & $\mathrm{X}$ & NP & Zoocórica \\
\hline Ocotea elegans $\mathrm{Mez}$ & Lima 2289 & $\mathrm{x}$ & $\mathrm{x}$ & NP & Zoocórica \\
\hline Ocotea glaziovii $\mathrm{Mez}$ & Lima 1877 & $\mathrm{x}$ & $\mathrm{x}$ & NP & Zoocórica \\
\hline Ocotea laxa (Nees) Mez & Lima 2203 & $\mathrm{x}$ & $\mathrm{x}$ & NP & Zoocórica \\
\hline Ocotea paranapiacabensis Coe-Teixeira & Lima 2258 & $\mathrm{x}$ & $\mathrm{x}$ & NP & Zoocórica \\
\hline Ocotea pulchella (Nees) Mez & Lima 1740 & - & $\mathrm{x}$ & $\mathrm{P}$ & Zoocórica \\
\hline Ocotea $\mathrm{sp} .1$ & Lima 2311 & $\mathrm{x}$ & - & $\mathrm{NC}$ & Zoocórica \\
\hline Ocotea teleiandra (Meisn.) Mez & Lima 1408 & - & $\mathrm{x}$ & NP & Zoocórica \\
\hline Lauraceae sp.1 & Lima 1244 & - & $\mathrm{x}$ & $\mathrm{NC}$ & Zoocórica \\
\hline Lauraceae sp.2 & - & - & $\mathrm{x}$ & $\mathrm{NC}$ & Zoocórica \\
\hline \multicolumn{6}{|l|}{ MALPIGHIACEAE } \\
\hline Byrsonima myricifolia Griseb. & Lima 1876 & $\mathrm{x}$ & - & NP & Zoocórica \\
\hline \multicolumn{6}{|l|}{ MALVACEAE } \\
\hline Eriotheca pentaphylla (Vell.) A. Robyns & Lima 2285 & - & $\mathrm{x}$ & $\mathrm{P}$ & Anemocórica \\
\hline Quararibea turbinata (Sw.) Poir. & Lima 1600 & - & $\mathrm{x}$ & $\mathrm{NC}$ & Zoocórica \\
\hline \multicolumn{6}{|l|}{ MELASTOMATACEAE } \\
\hline Miconia cabucu Hoehne & Lima 1999 & $\mathrm{x}$ & $\mathrm{x}$ & $\mathrm{P}$ & Zoocórica \\
\hline Miconia cinnamomifolia (DC.) Naudin & Lima 1862 & $\mathrm{x}$ & - & NP & Zoocórica \\
\hline Miconia cubatanensis Hoehne & Lima 2021 & $\mathrm{x}$ & - & $\mathrm{P}$ & Zoocórica \\
\hline Miconia discolor DC. & Lima 1670 & - & $\mathrm{x}$ & $\mathrm{NC}$ & Zoocórica \\
\hline Miconia ligustroides (DC.) Naudin & - & $\mathrm{x}$ & - & $\mathrm{P}$ & Zoocórica \\
\hline Miconia theaezans (Bonpl.) Cogn. & Lima 1571 & $\mathrm{x}$ & - & $\mathrm{P}$ & Zoocórica \\
\hline Miconia tristis Spring & Lima 1398 & - & $\mathrm{x}$ & $\mathrm{NC}$ & Zoocórica \\
\hline Mouriri chamissoana Cogn. & Lima 2101 & $\mathrm{x}$ & $\mathrm{x}$ & NP & Zoocórica \\
\hline Tibouchina pulchra (Cham.) Cogn. & Lima 2099 & $\mathrm{x}$ & $\mathrm{x}$ & $\mathrm{P}$ & Anemocórica \\
\hline Tibouchina sellowiana Cogn. & Lima 2017 & $\mathrm{x}$ & - & $\mathrm{P}$ & Anemocórica \\
\hline \multicolumn{6}{|l|}{ MELIACEAE } \\
\hline Cabralea canjerana (Vell.) Mart. & Lima 2267 & $\mathrm{x}$ & $\mathrm{x}$ & NP & Zoocórica \\
\hline Cedrela odorata $\mathrm{L}$. & Lima 2042 & $\mathrm{x}$ & - & NP & Anemocórica \\
\hline Guarea macrophylla Vahl & Lima 2041 & $\mathrm{x}$ & $\mathrm{x}$ & NP & Zoocórica \\
\hline
\end{tabular}


Tabela 1 (continuação)

\begin{tabular}{|c|c|c|c|c|c|}
\hline \multirow[t]{2}{*}{ Família/Espécie } & \multirow[t]{2}{*}{ Número de coletor } & \multicolumn{2}{|c|}{ Parcelas } & \multirow{2}{*}{$\begin{array}{l}\text { Categegorias } \\
\text { sucessionais }\end{array}$} & \multirow{2}{*}{$\begin{array}{c}\text { Síndrome de } \\
\text { dispersão }\end{array}$} \\
\hline & & $\mathrm{P} 1$ & $\mathrm{P} 2$ & & \\
\hline \multicolumn{6}{|l|}{ MONIMIACEAE } \\
\hline Mollinedia schottiana (Spreng.) Perkins & Lima 1976 & $\mathrm{X}$ & $\mathrm{x}$ & NP & Zoocórica \\
\hline Mollinedia triflora (Spreng.) Tul. & Lima 1645 & $\mathrm{x}$ & $\mathrm{x}$ & NP & Zoocórica \\
\hline Mollinedia uleana Perkins & Lima 2269 & $\mathrm{x}$ & $\mathrm{x}$ & NP & Zoocórica \\
\hline \multicolumn{6}{|l|}{ MORACEAE } \\
\hline Coussapoa microcarpa (Schott) Rizzini & Lima 1944 & $\mathrm{X}$ & - & NP & Zoocórica \\
\hline Ficus luschnathiana (Miq.) Miq. & Lima 1132 & $\mathrm{x}$ & - & NP & Zoocórica \\
\hline \multicolumn{6}{|l|}{ MYRSINACEAE } \\
\hline Rapanea ferruginea (Ruiz \& Pav.) Mez & Lima 2214 & $\mathrm{x}$ & $\mathrm{x}$ & $\mathrm{P}$ & Zoocórica \\
\hline Rapanea gardneriana (A. DC.) $\mathrm{Mez}$ & Lima 1952 & $\mathrm{x}$ & - & $\mathrm{P}$ & Zoocórica \\
\hline Rapanea hermogenesii Jung-Mend. \& Bernacci & Lima 2122 & $\mathrm{x}$ & $\mathrm{x}$ & NP & Zoocórica \\
\hline Rapanea umbellata (Mart.) Mez & Lima 1865 & $\mathrm{x}$ & $\mathrm{x}$ & $\mathrm{P}$ & Zoocórica \\
\hline Rapanea venosa (A. DC.) Mez & Lima 1585 & $\mathrm{x}$ & - & NP & Zoocórica \\
\hline \multicolumn{6}{|l|}{ MYRTACEAE } \\
\hline Blepharocalyx salicifolius (Kunth) O. Berg & Lima 2188 & $\mathrm{x}$ & $\mathrm{x}$ & NP & Zoocórica \\
\hline Calyptranthes fusiformis M.L. Kawas. & Lima 2275 & - & $\mathrm{x}$ & NP & Zoocórica \\
\hline Calyptranthes grandifolia $\mathrm{O}$. Berg & Lima 2278 & - & $\mathrm{x}$ & NP & Zoocórica \\
\hline Calyptranthes lucida Mart. ex DC. & Lima 2186 & $\mathrm{x}$ & $\mathrm{x}$ & NP & Zoocórica \\
\hline Campomanesia guaviroba (DC.) Kiaersk. & Lima 1710 & $\mathrm{x}$ & $\mathrm{x}$ & NP & Zoocórica \\
\hline Campomanesia phaea (O. Berg) Landrum & Lima 2294 & $\mathrm{x}$ & - & NP & Zoocórica \\
\hline Eugenia bocainensis Mattos & Lima 1456 & - & $\mathrm{X}$ & NP & Zoocórica \\
\hline Eugenia cf. burkartiana (D. Legrand) D. Legrand & Lima 2140 & $\mathrm{x}$ & $\mathrm{x}$ & NP & Zoocórica \\
\hline Eugenia cerasiflora Miq. & Lima 1817 & $\mathrm{x}$ & $\mathrm{x}$ & NP & Zoocórica \\
\hline Eugenia cf. malacantha D. Legrand & Lima 1428 & - & $\mathrm{x}$ & NP & Zoocórica \\
\hline Eugenia mosenii (Kausel) Sobral & Lima 599 & - & $\mathrm{x}$ & NP & Zoocórica \\
\hline Eugenia neoglomerata Sobral & Lima 2195 & - & $\mathrm{x}$ & NP & Zoocórica \\
\hline Eugenia pseudomalacantha D. Legrand & Lima 2276 & $\mathrm{x}$ & $\mathrm{x}$ & NP & Zoocórica \\
\hline Eugenia riedeliana $\mathrm{O}$. Berg & Lima 1758 & $\mathrm{x}$ & - & $\mathrm{NC}$ & Zoocórica \\
\hline Eugenia stictosepala Kiaersk. & Lima 2181 & - & $\mathrm{x}$ & NP & Zoocórica \\
\hline Eugenia stigmatosa DC. & Lima 1786 & $\mathrm{X}$ & - & $\mathrm{NC}$ & Zoocórica \\
\hline Eugenia subavenia $\mathrm{O}$. Berg & Lima 1450 & - & $\mathrm{x}$ & NP & Zoocórica \\
\hline Eugenia sp.1 & Lima 2107 & - & $\mathrm{x}$ & $\mathrm{NC}$ & Zoocórica \\
\hline Gomidesia flagellaris D. Legrand & Lima 1992 & - & $\mathrm{x}$ & NP & Zoocórica \\
\hline Gomidesia tijucensis (Kiaersk.) D. Legrand & Lima 2141 & $\mathrm{x}$ & $\mathrm{x}$ & NP & Zoocórica \\
\hline Marlierea excoriata Mart. & Lima 2277 & $\mathrm{x}$ & $\mathrm{x}$ & $\mathrm{NC}$ & Zoocórica \\
\hline Marlierea cf. obscura O. Berg & Lima 1494 & $\mathrm{x}$ & - & $\mathrm{NC}$ & Zoocórica \\
\hline Marlierea silvatica (Gardner) Kiaersk. & Lima 2236 & - & $\mathrm{X}$ & $\mathrm{NC}$ & Zoocórica \\
\hline Marlierea tomentosa Cambess. & - & $\mathrm{x}$ & - & $\mathrm{NC}$ & Zoocórica \\
\hline Myrceugenia miersiana (Gardner) D. Legrand \& Kausel & Lima 2164 & $\mathrm{x}$ & $\mathrm{x}$ & $\mathrm{NC}$ & Zoocórica \\
\hline Myrceugenia myrcioides (Cambess.) O. Berg & Lima 1386 & $\mathrm{X}$ & $\mathrm{X}$ & NP & Zoocórica \\
\hline Myrcia bicarinata (O.Berg) D. Legrand & Lima 2279 & $\mathrm{x}$ & $\mathrm{X}$ & $\mathrm{NC}$ & Zoocórica \\
\hline Myrcia brasiliensis Kiaersk. & Lima 2019 & $\mathrm{x}$ & - & $\mathrm{NC}$ & Zoocórica \\
\hline Myrcia fallax (Rich.) DC. & Lima 2184 & $\mathrm{x}$ & $\mathrm{x}$ & $\mathrm{P}$ & Zoocórica \\
\hline Myrcia cf. insularis Gardner & Lima 1307 & $\mathrm{x}$ & - & $\mathrm{NC}$ & Zoocórica \\
\hline Myrcia pubipetala Miq. & Lima 1839 & $\mathrm{x}$ & $\mathrm{x}$ & $\mathrm{NC}$ & Zoocórica \\
\hline Myrcia pulchra (O. Berg) Kiaersk. & Lima 1531 & $\mathrm{x}$ & - & $\mathrm{NC}$ & Zoocórica \\
\hline Myrcia cf. richardiana (O.Berg) Kiaersk. & Lima 1676 & - & $\mathrm{x}$ & NP & Zoocórica \\
\hline Myrcia spectabilis DC. & Lima 1871 & $\mathrm{x}$ & $\mathrm{x}$ & $\mathrm{NC}$ & Zoocórica \\
\hline Myrcia tijucensis Kiaersk. & Lima 1396 & $\mathrm{X}$ & $\mathrm{X}$ & $\mathrm{NC}$ & Zoocórica \\
\hline Myrciaria floribunda (H. West ex Willd.) O. Berg & Lima 2281 & - & $\mathrm{x}$ & NP & Zoocórica \\
\hline Neomitranthes cf. amblymitra (Burret) Mattos & Lima 1881 & $\mathrm{x}$ & $\mathrm{x}$ & $\mathrm{NC}$ & Zoocórica \\
\hline Neomitranthes glomerata (D. Legrand) D. Legrand & Lima 1366 & $\mathrm{x}$ & - & $\mathrm{P}$ & Zoocórica \\
\hline Psidium cattleianum Sabine & Lima 2005 & $\mathrm{x}$ & - & $\mathrm{P}$ & Zoocórica \\
\hline Myrtaceae sp.1 & Lima 2015 & $\mathrm{x}$ & - & $\mathrm{NC}$ & Zoocórica \\
\hline Myrtaceae sp.2 & - & $\mathrm{x}$ & - & $\mathrm{NC}$ & $\begin{array}{r}\text { Zoocórica } \\
\text { contin }\end{array}$ \\
\hline
\end{tabular}


Tabela 1 (continuação)

\begin{tabular}{|c|c|c|c|c|c|}
\hline \multirow[t]{2}{*}{ Família/Espécie } & \multirow[t]{2}{*}{ Número de coletor } & \multicolumn{2}{|c|}{ Parcelas } & \multirow{2}{*}{$\begin{array}{l}\text { Categegorias } \\
\text { sucessionais }\end{array}$} & \multirow{2}{*}{$\begin{array}{l}\text { Síndrome de } \\
\text { dispersão }\end{array}$} \\
\hline & & $\mathrm{P} 1$ & $\mathrm{P} 2$ & & \\
\hline Myrtaceae sp.3 & Lima 1251 & - & $\mathrm{x}$ & $\mathrm{NC}$ & Zoocórica \\
\hline Myrtaceae sp.4 & Lima 1248 & - & $\mathrm{x}$ & $\mathrm{NC}$ & Zoocórica \\
\hline Myrtaceae sp. 5 & - & - & $\mathrm{x}$ & $\mathrm{NC}$ & Zoocórica \\
\hline Myrtaceae sp.6 & - & - & $\mathrm{x}$ & $\mathrm{NC}$ & Zoocórica \\
\hline \multicolumn{6}{|l|}{ NYCTAGINACEAE } \\
\hline Guapira nitida (Schmidt) Lundell & Lima 2198 & - & $\mathrm{x}$ & NP & Zoocórica \\
\hline Guapira opposita (Vell.) Reitz & Lima 1853 & $\mathrm{x}$ & $\mathrm{x}$ & NP & Zoocórica \\
\hline \multicolumn{6}{|l|}{ OCHNACEAE } \\
\hline Ouratea multiflora (A. St.-Hil.) Engl. & Lima 1668 & - & $\mathrm{x}$ & NP & Zoocórica \\
\hline \multicolumn{6}{|l|}{ OLACACEAE } \\
\hline Heisteria silvianii Schwacke & Lima 2227 & $\mathrm{x}$ & $\mathrm{x}$ & NP & Zoocórica \\
\hline Schoepfia brasiliensis A. DC. & Lima 1748 & - & $\mathrm{x}$ & NP & Zoocórica \\
\hline \multicolumn{6}{|l|}{ OLEACEAE } \\
\hline Chionanthus filiformis (Vell.) P.S. Green & Lima 1611 & - & $\mathrm{x}$ & NP & Zoocórica \\
\hline \multicolumn{6}{|l|}{ PHYLLANTHACEAE } \\
\hline Hieronyma alchorneoides Allemão & Lima 2213 & $\mathrm{x}$ & $\mathrm{x}$ & $\mathrm{P}$ & Zoocórica \\
\hline \multicolumn{6}{|l|}{ PICRAMNIACEAE } \\
\hline Picramnia gardneri Planch. & Lima 1560 & $\mathrm{x}$ & - & NP & Zoocórica \\
\hline \multicolumn{6}{|l|}{ POLYGONACEAE } \\
\hline Coccoloba glaziovii Lindau & Lima 2235 & - & $\mathrm{x}$ & $\mathrm{P}$ & Zoocórica \\
\hline \multicolumn{6}{|l|}{ PROTEACEAE } \\
\hline Euplassa hoehnei Sleumer & Lima 2179 & $\mathrm{x}$ & $\mathrm{x}$ & NP & Zoocórica \\
\hline Roupala montana Aubl. & - & $\mathrm{x}$ & - & $\mathrm{P}$ & Anemocórica \\
\hline \multicolumn{6}{|l|}{ ROSACEAE } \\
\hline Prunus myrtifolia (L.) Urb. & Lima 2155 & $\mathrm{x}$ & $\mathrm{x}$ & $\mathrm{P}$ & Zoocórica \\
\hline \multicolumn{6}{|l|}{ RUBIACEAE } \\
\hline Alibertia myrciifolia Spruce ex K. Schum. & Lima 1468 & $\mathrm{x}$ & - & NP & Zoocórica \\
\hline Alseis floribunda Schott & Lima 2268 & - & $\mathrm{x}$ & $\mathrm{P}$ & Anemocórica \\
\hline Amaioua intermedia Mart. & Lima 1323 & $\mathrm{x}$ & $\mathrm{x}$ & NP & Zoocórica \\
\hline Bathysa stipulata (Vell.) C. Presl & Lima 2146 & $\mathrm{x}$ & $\mathrm{x}$ & $\mathrm{P}$ & Anemocórica \\
\hline Chomelia pohliana Müll. Arg. & Lima 1677 & $\mathrm{x}$ & $\mathrm{x}$ & $\mathrm{P}$ & Zoocórica \\
\hline Coussarea contracta (Walp.) Müll. Arg. & Lima 2167 & $\mathrm{x}$ & $\mathrm{x}$ & NP & Zoocórica \\
\hline Faramea tetragona Müll. Arg. & Lima 2145 & $\mathrm{x}$ & $\mathrm{x}$ & NP & Zoocórica \\
\hline Ixora heterodoxa Müll. Arg. & Lima 1443 & $\mathrm{x}$ & - & $\mathrm{NC}$ & Zoocórica \\
\hline Posoqueria latifolia (Rudge) Roem. \& Schult. & Lima 1558 & $\hat{x}$ & - & NP & Zoocórica \\
\hline Psychotria nuda (Cham. \& Schltdl.) Wawra & Lima 2330 & $\mathrm{x}$ & - & NP & Zoocórica \\
\hline Psychotria suterella Müll. Arg. & Lima 1327 & $\mathrm{x}$ & $\mathrm{x}$ & NP & Zoocórica \\
\hline Psychotria vellosiana Benth. & Lima 1787 & $\mathrm{x}$ & - & $\mathrm{NC}$ & Zoocórica \\
\hline Rudgea gardenioides (Cham.) Müll. Arg. & Lima 1268 & - & $\mathrm{x}$ & NP & Zoocórica \\
\hline Rudgea jasminoides (Cham.) Müll. Arg. & Lima 2259 & $\mathrm{x}$ & $\mathrm{x}$ & NP & Zoocórica \\
\hline \multicolumn{6}{|l|}{ SALICACEAE } \\
\hline Casearia sylvestris $\mathrm{Sw}$. & Lima 2110 & $\mathrm{x}$ & $\mathrm{x}$ & $\mathrm{P}$ & Zoocórica \\
\hline Xylosma cf. glaberrima Sleumer & - & $\mathrm{x}$ & - & $\mathrm{P}$ & Zoocórica \\
\hline \multicolumn{6}{|l|}{ SAPINDACEAE } \\
\hline Allophylus petiolulatus Radlk. & Lima 1591 & $\mathrm{x}$ & $\mathrm{x}$ & NP & Zoocórica \\
\hline Cupania furfuracea Radlk. & Lima 2216 & $\mathrm{x}$ & $\mathrm{x}$ & $\mathrm{NC}$ & Zoocórica \\
\hline Cupania oblongifolia Mart. & Lima 2228 & $\mathrm{x}$ & $\mathrm{x}$ & $\mathrm{P}$ & Zoocórica \\
\hline Matayba juglandifolia Radlk. & Lima 2148 & $\mathrm{x}$ & $\mathrm{x}$ & $\mathrm{P}$ & Zoocórica \\
\hline \multicolumn{6}{|l|}{ SAPOTACEAE } \\
\hline Chrysophyllum flexuosum Mart. & Lima 1685 & - & $\mathrm{x}$ & NP & Zoocórica \\
\hline Chrysophyllum inornatum Mart. & Lima 2134 & - & $\mathrm{x}$ & NP & Zoocórica \\
\hline SAPOTACEAE & & & & & \\
\hline Ecclinusa ramiflora Mart. & Lima 2187 & - & $\mathrm{x}$ & $\mathrm{NC}$ & Zoocórica \\
\hline Pouteria cf. bullata (S. Moore) Baehni & Lima 1415 & - & $\mathrm{x}$ & NP & Zoocórica \\
\hline
\end{tabular}


Tabela 1 (continuação)

\begin{tabular}{|c|c|c|c|c|c|}
\hline \multirow[t]{2}{*}{ Família/Espécie } & \multirow[t]{2}{*}{ Número de coletor } & \multicolumn{2}{|c|}{ Parcelas } & \multirow{2}{*}{$\begin{array}{l}\text { Categegorias } \\
\text { sucessionais }\end{array}$} & \multirow{2}{*}{$\begin{array}{c}\text { Síndrome de } \\
\text { dispersão }\end{array}$} \\
\hline & & $\mathrm{P} 1$ & $\mathrm{P} 2$ & & \\
\hline \multicolumn{6}{|l|}{ SOLANACEAE } \\
\hline Aureliana fasciculata (Vell.) Sendtn. & Lima 1760 & $\mathrm{x}$ & - & $\mathrm{P}$ & Zoocórica \\
\hline Solanum cinnamomeum Sendtn. & Lima 1971 & - & $\mathrm{x}$ & $\mathrm{P}$ & Zoocórica \\
\hline Solanum pseudoquina A. St.-Hil. & Lima 2308 & $\mathrm{x}$ & - & $\mathrm{P}$ & Zoocórica \\
\hline Solanum rufescens Sendtn. & Lima 1640 & - & $\mathrm{x}$ & $\mathrm{P}$ & Zoocórica \\
\hline \multicolumn{6}{|l|}{ SYMPLOCACEAE } \\
\hline Symplocos laxiflora Benth. & Lima 1368 & $\mathrm{x}$ & - & $\mathrm{NC}$ & Zoocórica \\
\hline \multicolumn{6}{|l|}{ THEACEAE } \\
\hline Gordonia fruticosa (Schrad.) H. Keng & Lima 2325 & - & $\mathrm{x}$ & NP & Zoocórica \\
\hline \multicolumn{6}{|l|}{ THYMELAEACEAE } \\
\hline Daphnopsis schwackeana Taub. & Lima 2241 & $\mathrm{x}$ & - & NP & Zoocórica \\
\hline \multicolumn{6}{|l|}{ URTICACEAE } \\
\hline Cecropia pachystachya Trécul & Lima 2260 & - & $\mathrm{x}$ & $\mathrm{P}$ & Zoocórica \\
\hline \multicolumn{6}{|l|}{ VERBENACEAE } \\
\hline Aegiphila sellowiana Cham. & Lima 1493 & $\mathrm{x}$ & $\mathrm{x}$ & $\mathrm{P}$ & Zoocórica \\
\hline \multicolumn{6}{|l|}{ WINTERACEAE } \\
\hline Drimys brasiliensis Miers & Lima 1284 & $\mathrm{X}$ & - & $\mathrm{P}$ & Zoocórica \\
\hline
\end{tabular}

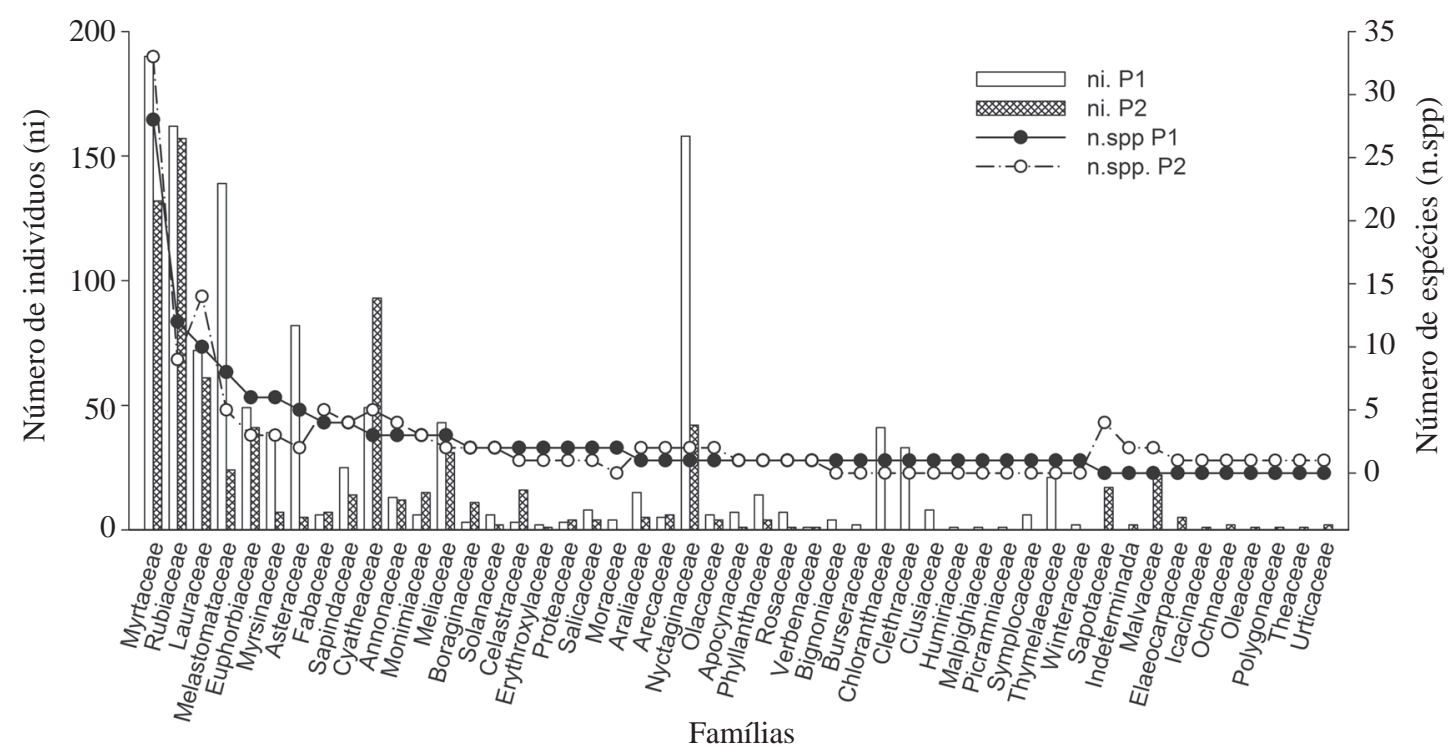

Figura 2. Número de indivíduos e espécies por família em P1 e P2.

Figure 2. Number of individuals and species in each family in P1 and P2.

$12,82 \%)$ e $\mathrm{P} 2(57,48 \pm 8,50 \%)$ (tabela 4 , figura 3 ). Síndromes de dispersão - A média da porcentagem do número de indivíduos que apresentam síndrome de dispersão zoocórica é maior tanto em P1 (78,58 \pm $18,43 \%)$ quanto em P2 $(81,06 \pm 8,50 \%)$, sobre a anemocórica, com $17,78 \pm 7,48 \%$ e $13,38 \pm 4,98 \%$ dos indivíduos amostrados para P1 e P2, respectivamente (tabela 4 , figura 3 ).

Classes de altura e diâmetro - Quanto às classes de altura, a amplitude variou de 2 a $25 \mathrm{~m}$ na parcela P1 e de 2 a $28 \mathrm{~m}$ na parcela P2. De acordo com os histogramas de freqüência de altura, nas duas parcelas $33 \%$ dos indivíduos estão representados na segunda classe de altura, que corresponde a 4,6-7,2 m. As espécies Guapira opposita e Psychotria suterella representam $36 \%$ dos indivíduos da parcela $\mathrm{P} 1$, enquanto em P2 Bathysa stipulata corresponde a $38 \%$ dos indivíduos (figura 4).

Em relação ao diâmetro, a amplitude em $\mathrm{P} 1$ variou de 4,8 a $60,2 \mathrm{~cm}$ e em $\mathrm{P} 2$ de 4,8 a $79,0 \mathrm{~cm}$. O histograma de frequência de diâmetro apresenta grande concentração dos indivíduos na primeira classe 
Tabela 2. Parâmetros fitossociológicos das espécies arbóreas amostradas na parcela P1 do Parque Natural Municipal Nascentes de Paranapiacaba, Santo André, SP, Brasil. Ni: número de indivíduos amostrados; Npar: número de subparcelas de ocorrência; DR: densidade relativa (\%); FR: frequência relativa (\%); DoR: dominância relativa (\%); VI: valor de importância (\%); VC: valor de cobertura (\%). Table 2. Phytosociological parameters of tree species sampled in P1 plot of the Parque Natural Municipal Nascentes de Paranapiacaba, Santo André, SP, Brazil. Ni: number of individuals sampled; Npar: number of occurrence in the subplots; DR: relative density (\%); FR: relative frequency (\%); DoR: relative dominance (\%); VI: importance value (\%); VC: cover (\%).

\begin{tabular}{|c|c|c|c|c|c|c|c|}
\hline Espécies & $\mathrm{Ni}$ & Npar & DR & FR & DoR & VI & VC \\
\hline Miconia cabucu Hoehne & 75 & 19 & 6,06 & 3,40 & 18,19 & 27,65 & 24,25 \\
\hline Guapira opposita (Vell.) Reitz & 158 & 22 & 12,77 & 3,94 & 8,89 & 25,60 & 21,66 \\
\hline Psychotria suterella Müll. Arg. & 130 & 20 & 10,51 & 3,58 & 3,43 & 17,52 & 13,94 \\
\hline Tibouchina pulchra (Cham.) Cogn. & 44 & 12 & 3,56 & 2,15 & 5,13 & 10,83 & 8,68 \\
\hline Croton macrobothrys Baill. & 10 & 6 & 0,81 & 1,07 & 8,25 & 10,13 & 9,06 \\
\hline Cyathea delgadii Sternb. & 32 & 13 & 2,59 & 2,33 & 3,96 & 8,87 & 6,55 \\
\hline Myrcia pubipetala Miq. & 52 & 15 & 4,20 & 2,68 & 1,92 & 8,81 & 6,12 \\
\hline Ocotea paranapiacabensis Coe-Teixeira & 41 & 16 & 3,31 & 2,86 & 2,31 & 8,49 & 5,63 \\
\hline Hedyosmum brasiliense Mart. ex Miq. & 41 & 13 & 3,31 & 2,33 & 2,31 & 7,95 & 5,63 \\
\hline Vernonanthura puberula (Less.) H. Rob. & 24 & 11 & 1,94 & 1,97 & 3,85 & 7,76 & 5,79 \\
\hline Myrciafallax (Rich.) DC. & 38 & 16 & 3,07 & 2,86 & 1,65 & 7,58 & 4,72 \\
\hline Rapanea umbellata (Mart.) Mez & 22 & 15 & 1,78 & 2,68 & 2,67 & 7,13 & 4,45 \\
\hline Alchornea triplinervia (Spreng.) Müll. Arg. & 19 & 13 & 1,54 & 2,33 & 3,00 & 6,86 & 4,54 \\
\hline Guarea macrophylla Vahl & 29 & 16 & 2,34 & 2,86 & 1,21 & 6,42 & 3,56 \\
\hline Clethra scabra Pers. & 33 & 9 & 2,67 & 1,61 & 2,10 & 6,38 & 4,77 \\
\hline Baccharis oreophila Malme & 44 & 5 & 3,56 & 0,89 & 1,68 & 6,13 & 5,24 \\
\hline Daphnopsis schwackeana Taub. & 21 & 14 & 1,70 & 2,50 & 1,04 & 5,24 & 2,74 \\
\hline Myrcia brasiliensis Kiaersk. & 16 & 12 & 1,29 & 2,15 & 0,97 & 4,41 & 2,26 \\
\hline Matayba juglandifolia Radlk. & 14 & 10 & 1,13 & 1,79 & 1,43 & 4,35 & 2,56 \\
\hline Myrcia spectabilis DC. & 18 & 11 & 1,46 & 1,97 & 0,91 & 4,33 & 2,36 \\
\hline Cabralea canjerana (Vell.) Mart. & 13 & 11 & 1,05 & 1,97 & 0,95 & 3,97 & 2,00 \\
\hline Schefflera angustissima (Marchal) Frodin & 15 & 9 & 1,21 & 1,61 & 1,11 & 3,93 & 2,32 \\
\hline Hieronyma alchorneoides Allemão & 14 & 10 & 1,13 & 1,79 & 0,91 & 3,83 & 2,04 \\
\hline Sapium glandulosum (L.) Morong & 12 & 8 & 0,97 & 1,43 & 1,31 & 3,71 & 2,28 \\
\hline Calyptranthes lucida Mart. ex DC. & 16 & 11 & 1,29 & 1,97 & 0,34 & 3,60 & 1,63 \\
\hline Psidium cattleianum Sabine & 13 & 8 & 1,05 & 1,43 & 0,46 & 2,94 & 1,51 \\
\hline Cyathea phalerata Mart. & 11 & 8 & 0,89 & 1,43 & 0,57 & 2,89 & 1,46 \\
\hline Aspidosperma olivaceum Müll. Arg. & 7 & 7 & 0,57 & 1,25 & 1,06 & 2,88 & 1,62 \\
\hline Ocotea elegans $\mathrm{Mez}$ & 11 & 7 & 0,89 & 1,25 & 0,47 & 2,61 & 1,36 \\
\hline Piptocarpha axillaris (Less.) Baker & 7 & 5 & 0,57 & 0,89 & 0,99 & 2,45 & 1,55 \\
\hline Miconia cinnamomifolia (DC.) Naudin & 4 & 4 & 0,32 & 0,72 & 1,38 & 2,42 & 1,70 \\
\hline Vernonanthura divaricata (Spreng.) H. Rob. & 6 & 4 & 0,49 & 0,72 & 1,14 & 2,34 & 1,62 \\
\hline Chomelia pohliana Müll. Arg. & 8 & 5 & 0,65 & 0,89 & 0,61 & 2,16 & 1,26 \\
\hline Rapanea ferruginea (Ruiz \& Pav.) Mez & 6 & 6 & 0,49 & 1,07 & 0,45 & 2,01 & 0,94 \\
\hline Neomitranthes amblymitra (Burret) Mattos & 7 & 6 & 0,57 & 1,07 & 0,37 & 2,01 & 0,93 \\
\hline Clusia criuva Cambess. & 8 & 4 & 0,65 & 0,72 & 0,60 & 1,97 & 1,25 \\
\hline Prunus myrtifolia (L.) Urb. & 7 & 6 & 0,57 & 1,07 & 0,30 & 1,94 & 0,87 \\
\hline Heisteria silvianii Schwacke & 6 & 6 & 0,49 & 1,07 & 0,28 & 1,84 & 0,76 \\
\hline Alchornea glandulosa Poepp. & 4 & 3 & 0,32 & 0,54 & 0,92 & 1,78 & 1,25 \\
\hline Casearia sylvestris $\mathrm{Sw}$. & 7 & 5 & 0,57 & 0,89 & 0,25 & 1,71 & 0,82 \\
\hline Solanum pseudoquina A. St.-Hil. & 5 & 3 & 0,40 & 0,54 & 0,67 & 1,61 & 1,08 \\
\hline Cyathea atrovirens (Langsd. \& Fisch.) Domin & 6 & 3 & 0,49 & 0,54 & 0,53 & 1,55 & 1,01 \\
\hline Annona neosericea $\mathrm{H}$. Rainer & 6 & 4 & 0,49 & 0,72 & 0,23 & 1,43 & 0,72 \\
\hline Jacaranda puberula Cham. & 4 & 4 & 0,32 & 0,72 & 0,37 & 1,41 & 0,69 \\
\hline Symplocos laxiflora Benth. & 6 & 4 & 0,49 & 0,72 & 0,17 & 1,37 & 0,65 \\
\hline Rapanea venosa (A. DC.) Mez & 6 & 3 & 0,49 & 0,54 & 0,33 & 1,35 & 0,82 \\
\hline Guatteria elliptica R.E. Fr. & 6 & 4 & 0,49 & 0,72 & 0,12 & 1,33 & 0,61 \\
\hline Inga sessilis (Vell.) Mart. & 3 & 3 & 0,24 & 0,54 & 0,48 & 1,26 & 0,73 \\
\hline Ocotea glaziovii Mez & 5 & 4 & 0,40 & 0,72 & 0,13 & 1,25 & 0,53 \\
\hline Cupania oblongifolia Mart. & 5 & 4 & 0,40 & 0,72 & 0,13 & 1,25 & 0,53 \\
\hline
\end{tabular}


Tabela 2 (continuação)

\begin{tabular}{|c|c|c|c|c|c|c|c|}
\hline Espécies & $\mathrm{Ni}$ & Npar & DR & FR & DoR & VI & $\mathrm{VC}$ \\
\hline Ixora heterodoxa Müll. Arg. & 4 & 4 & 0,32 & 0,72 & 0,16 & 1,20 & 0,48 \\
\hline Ocotea dispersa (Ness) Mez. & 6 & 3 & 0,49 & 0,54 & 0,16 & 1,18 & 0,65 \\
\hline Cedrela odorata $\mathrm{L}$ & 1 & 1 & 0,08 & 0,18 & 0,89 & 1,15 & 0,97 \\
\hline Rapanea gardneriana (A. DC.) Mez & 3 & 3 & 0,24 & 0,54 & 0,30 & 1,08 & 0,54 \\
\hline Miconia ligustroides (DC.) Naudin & 7 & 2 & 0,57 & 0,36 & 0,13 & 1,05 & 0,70 \\
\hline Campomanesia guaviroba (DC.) Kiaersk. & 3 & 3 & 0,24 & 0,54 & 0,18 & 0,96 & 0,42 \\
\hline Allophylus petiolulatus Radlk. & 4 & 3 & 0,32 & 0,54 & 0,09 & 0,95 & 0,41 \\
\hline Coussarea contracta (Walp.) Müll. Arg. & 4 & 3 & 0,32 & 0,54 & 0,07 & 0,93 & 0,40 \\
\hline Eugenia cerasiflora Miq. & 3 & 3 & 0,24 & 0,54 & 0,11 & 0,89 & 0,35 \\
\hline Bathysa stipulata (Vell.) C. Presl & 4 & 2 & 0,32 & 0,36 & 0,19 & 0,87 & 0,51 \\
\hline Ficus luschnathiana (Miq.) Miq. & 3 & 3 & 0,24 & 0,54 & 0,09 & 0,87 & 0,34 \\
\hline Tibouchina sellowiana Cogn. & 3 & 2 & 0,24 & 0,36 & 0,27 & 0,87 & 0,51 \\
\hline Bactris setosa Mart. & 5 & 2 & 0,40 & 0,36 & 0,08 & 0,85 & 0,49 \\
\hline Psychotria vellosiana Benth. & 3 & 3 & 0,24 & 0,54 & 0,06 & 0,84 & 0,31 \\
\hline Eugenia cf. burkartiana (D. Legrand) D. Legrand & 3 & 3 & 0,24 & 0,54 & 0,06 & 0,84 & 0,31 \\
\hline Miconia theaezans (Bonpl.) Cogn. & 3 & 3 & 0,24 & 0,54 & 0,06 & 0,84 & 0,30 \\
\hline Ocotea laxa (Nees) Mez & 3 & 2 & 0,24 & 0,36 & 0,20 & 0,80 & 0,44 \\
\hline Protium heptaphyllum (Aubl.) Marchand & 2 & 2 & 0,16 & 0,36 & 0,23 & 0,75 & 0,39 \\
\hline Alchornea sidifolia Müll. Arg. & 3 & 2 & 0,24 & 0,36 & 0,09 & 0,69 & 0,33 \\
\hline Maytenus robusta Reissek & 2 & 2 & 0,16 & 0,36 & 0,15 & 0,67 & 0,31 \\
\hline Cordia trichoclada DC. & 2 & 2 & 0,16 & 0,36 & 0,15 & 0,67 & 0,31 \\
\hline Mollinedia triflora (Spreng.) Tul. & 3 & 2 & 0,24 & 0,36 & 0,05 & 0,65 & 0,30 \\
\hline Cinnamomum glaziovii (Mez) Kosterm. & 2 & 2 & 0,16 & 0,36 & 0,10 & 0,62 & 0,26 \\
\hline Mollinedia uleana Perkins & 2 & 2 & 0,16 & 0,36 & 0,10 & 0,61 & 0,26 \\
\hline Neomitranthes glomerata (D. Legrand) D. Legrand & 2 & 2 & 0,16 & 0,36 & 0,09 & 0,61 & 0,25 \\
\hline Mouriri chamissoana Cogn. & 2 & 2 & 0,16 & 0,36 & 0,09 & 0,61 & 0,25 \\
\hline Eugenia stigmatosa DC. & 2 & 2 & 0,16 & 0,36 & 0,08 & 0,60 & 0,24 \\
\hline Drimys brasiliensis Miers & 2 & 2 & 0,16 & 0,36 & 0,07 & 0,59 & 0,23 \\
\hline Campomanesia phaea (O. Berg) Landrum & 2 & 2 & 0,16 & 0,36 & 0,04 & 0,56 & 0,20 \\
\hline Euplassa hoehnei Sleumer & 2 & 2 & 0,16 & 0,36 & 0,04 & 0,56 & 0,20 \\
\hline Psychotria nuda (Cham. \& Schltdl.) Wawra & 2 & 2 & 0,16 & 0,36 & 0,04 & 0,56 & 0,20 \\
\hline Amaioua intermedia Mart. & 2 & 2 & 0,16 & 0,36 & 0,03 & 0,55 & 0,20 \\
\hline Cupania furfuracea Radlk. & 2 & 2 & 0,16 & 0,36 & 0,03 & 0,55 & 0,19 \\
\hline Coussapoa microcarpa (Schott) Rizzini & 1 & 1 & 0,08 & 0,18 & 0,26 & 0,52 & 0,34 \\
\hline Senna multijuga (Rich.) H.S. Irwin \& Barneby & 1 & 1 & 0,08 & 0,18 & 0,23 & 0,49 & 0,31 \\
\hline Byrsonima myricifolia Griseb. & 1 & 1 & 0,08 & 0,18 & 0,22 & 0,48 & 0,30 \\
\hline Xylosma cf. glaberrima Sleumer & 1 & 1 & 0,08 & 0,18 & 0,20 & 0,46 & 0,28 \\
\hline Humiriastrum glaziovii (Urb.) Cuatrec. & 1 & 1 & 0,08 & 0,18 & 0,16 & 0,42 & 0,25 \\
\hline Aureliana fasciculata (Vell.) Sendtn. & 1 & 1 & 0,08 & 0,18 & 0,16 & 0,42 & 0,24 \\
\hline Alibertia myrciifolia Spruce ex K. Schum. & 2 & 1 & 0,16 & 0,18 & 0,06 & 0,40 & 0,23 \\
\hline Piptadenia paniculata Benth. & 1 & 1 & 0,08 & 0,18 & 0,11 & 0,37 & 0,19 \\
\hline Critoniopsis quinqueflora (Less.) H. Rob. & 1 & 1 & 0,08 & 0,18 & 0,10 & 0,36 & 0,18 \\
\hline Salacia grandifolia (Mart.) G. Don & 1 & 1 & 0,08 & 0,18 & 0,10 & 0,36 & 0,18 \\
\hline Sclerolobium denudatum Vogel & 1 & 1 & 0,08 & 0,18 & 0,07 & 0,33 & 0,15 \\
\hline Myrtaceae sp.2 & 1 & 1 & 0,08 & 0,18 & 0,06 & 0,32 & 0,14 \\
\hline Myrtaceae sp.1 & 1 & 1 & 0,08 & 0,18 & 0,06 & 0,32 & 0,14 \\
\hline Erythroxylum gonoclados (Mart.) O.E. Schulz & 1 & 1 & 0,08 & 0,18 & 0,06 & 0,32 & 0,14 \\
\hline Pera glabrata (Schott) Poepp. ex Baill. & 1 & 1 & 0,08 & 0,18 & 0,05 & 0,31 & 0,13 \\
\hline Aegiphila sellowiana Cham. & 1 & 1 & 0,08 & 0,18 & 0,05 & 0,31 & 0,13 \\
\hline Cordia sellowiana Cham. & 1 & 1 & 0,08 & 0,18 & 0,04 & 0,30 & 0,13 \\
\hline Ocotea sp.1 & 1 & 1 & 0,08 & 0,18 & 0,04 & 0,30 & 0,12 \\
\hline Rudgea jasminoides (Cham.) Müll. Arg. & 1 & 1 & 0,08 & 0,18 & 0,03 & 0,29 & 0,11 \\
\hline Guatteria polycarpa R.E. Fr. & 1 & 1 & 0,08 & 0,18 & 0,03 & 0,29 & 0,11 \\
\hline Cryptocarya saligna $\mathrm{Mez}$ & 1 & 1 & 0,08 & 0,18 & 0,03 & 0,29 & 0,11 \\
\hline Myrcia tijucensis Kiaersk. & 1 & 1 & 0,08 & 0,18 & 0,02 & 0,28 & 0,11 \\
\hline Eugenia riedeliana $\mathrm{O}$. Berg & 1 & 1 & 0,08 & 0,18 & 0,02 & 0,28 & $\begin{array}{r}0,10 \\
\text { conti }\end{array}$ \\
\hline
\end{tabular}


Tabela 2 (continuação)

\begin{tabular}{|c|c|c|c|c|c|c|c|}
\hline Espécies & $\mathrm{Ni}$ & Npar & DR & FR & DoR & VI & $\mathrm{VC}$ \\
\hline Miconia cubatanensis Hoehne & 1 & 1 & 0,08 & 0,18 & 0,02 & 0,28 & 0,10 \\
\hline Gomidesia tijucensis (Kiaersk.) D. Legrand & 1 & 1 & 0,08 & 0,18 & 0,02 & 0,28 & 0,10 \\
\hline Posoqueria latifolia (Rudge) Roem. \& Schult. & 1 & 1 & 0,08 & 0,18 & 0,02 & 0,28 & 0,10 \\
\hline Faramea tetragona Müll. Arg. & 1 & 1 & 0,08 & 0,18 & 0,02 & 0,28 & 0,10 \\
\hline Myrcia bicarinata (O. Berg) D. Legrand & 1 & 1 & 0,08 & 0,18 & 0,02 & 0,28 & 0,10 \\
\hline Marlierea excoriata Mart. & 1 & 1 & 0,08 & 0,18 & 0,02 & 0,28 & 0,10 \\
\hline Licaria cf. armeniaca (Nees) Kosterm. & 1 & 1 & 0,08 & 0,18 & 0,02 & 0,28 & 0,10 \\
\hline Myrcia cf. insularis Gardner & 1 & 1 & 0,08 & 0,18 & 0,02 & 0,28 & 0,10 \\
\hline Marlierea tomentosa Cambess. & 1 & 1 & 0,08 & 0,18 & 0,02 & 0,28 & 0,10 \\
\hline Blepharocalyx salicifolius (Kunth) O. Berg & 1 & 1 & 0,08 & 0,18 & 0,02 & 0,28 & 0,10 \\
\hline Ocotea bicolor Vattimo & 1 & 1 & 0,08 & 0,18 & 0,02 & 0,28 & 0,10 \\
\hline Roupala montana Aubl. & 1 & 1 & 0,08 & 0,18 & 0,02 & 0,28 & 0,10 \\
\hline Picramnia gardneri Planch. & 1 & 1 & 0,08 & 0,18 & 0,02 & 0,28 & 0,10 \\
\hline Myrcia pulchra (O. Berg) Kiaersk. & 1 & 1 & 0,08 & 0,18 & 0,02 & 0,28 & 0,10 \\
\hline Erythroxylum cuspidifolium Mart. & 1 & 1 & 0,08 & 0,18 & 0,02 & 0,28 & 0,10 \\
\hline Marlierea cf. obscura O. Berg & 1 & 1 & 0,08 & 0,18 & 0,01 & 0,27 & 0,10 \\
\hline Eugenia pseudomalacantha D. Legrand & 1 & 1 & 0,08 & 0,18 & 0,01 & 0,27 & 0,10 \\
\hline Rapanea hermogenesii Jung-Mend. \& Bernacci & 1 & 1 & 0,08 & 0,18 & 0,01 & 0,27 & 0,10 \\
\hline Myrceugenia myrcioides (Cambess.) O. Berg & 1 & 1 & 0,08 & 0,18 & 0,01 & 0,27 & 0,09 \\
\hline Myrceugenia miersiana (Gardner) D. Legrand \& Kausel & 1 & 1 & 0,08 & 0,18 & 0,01 & 0,27 & 0,09 \\
\hline Mollinedia schottiana (Spreng.) Perkins & 1 & 1 & 0,08 & 0,18 & 0,01 & 0,27 & 0,09 \\
\hline Total & 237 & 559 & 100,00 & 100,00 & 100,00 & 300,00 & 200,00 \\
\hline
\end{tabular}

de diâmetro $(4,8-11,5 \mathrm{~cm})$ tanto em P1 (76,0\%) quanto em P2 $(58,0 \%)$. Em P1 as espécies que mais contribuíram para a concentração dos diâmetros nesta classe foram Guapira opposita (14,4\%), Psychotria suterella $(16,15 \%)$, Baccharis oreophylla (5\%), Hedyosmum brasiliense (4,04\%), Ocotea paranapiacabensis $(3,5 \%)$ e Tibouchina pulchra $(2,57 \%)$ correspondendo a 45,66\% dos indivíduos amostrados. Em P2 as espécies que encontram-se nessa faixa de diâmetro são Bathysa stipulata, apresentando a maior frequência $(12,75 \%)$, seguida de Guapira opposita (7,5\%), Cyathea delgadii $(5,46 \%)$ e Psychotria suterella (2,9\%), em conjunto representando $28,61 \%$ dos indivíduos nessa classe de diâmetro (figura 5).

Análise de Agrupamento - A análise de agrupamento, com base nos dados de abundância obtidos nos trabalhos realizados na região da Serra do Mar sob influência da poluição de Cubatão, revela primeiramente dois grandes grupos, um deles reunindo os trabalhos realizados na Reserva Biológica do Alto da Serra de Paranapiacaba (RB-AB, RB-AR e $\mathrm{RB}-\mathrm{CN}$ ) e o outro com todos os trabalhos restantes realizados no vale do rio Mogi (VM e VM-LF), vale do rio Pilões (RP-LF1, RP-LF2, RP-LF3 e RP-Pomp), no PNMNP (P1 e P2) e Caminhos do Mar (CM). Avaliando esse grande grupo, verifica-se que o trabalho do rio Mogi (VM-LF) é o mais isolado, enquanto no grupo restante, há três subgrupos: P1 e P2, RP-LF3 e RP-Pomp, RP-LF1 e RP-LF2 (figura 6).

\section{Discussão}

Quando comparamos os resultados de riqueza e diversidade, o número de espécies e famílias é muito semelhante nas duas parcelas estudadas, porém, o número de indivíduos em P1 é muito superior (1.237) e representado principalmente por indivíduos jovens de espécies pioneiras de início de sucessão e espécies não pioneiras pertencentes ao sub-bosque, como Guapira opposita e Psychotria suterella que juntas representam $23,28 \%$ do total de indivíduos amostrados. O menor número de indivíduos em P2 (755) pode refletir uma condição sucessional mais avançada, porém, nas subparcelas F2, F3, G2, G3, G4, I2, I3, I4, $\mathrm{J} 2$ e J3 também existem formações dos bambus Merostachys neesii Rupr. e Chusquea urelytra Hack. que podem influenciar na estrutura e dinâmica da floresta, principalmente através do sombreamento e da formação de microhabitats para predadores de sementes e plântulas, interferindo no recrutamento de árvores (Rother et al. 2009).

Em relação à composição florística, o presente trabalho registrou o predomínio de espécies de Myrtaceae, seguida de Rubiaceae, Melastomataceae 
Tabela 3. Parâmetros fitossociológicos das espécies arbóreas amostradas na parcela P2 do Parque Natural Municipal Nascentes de Paranapiacaba, Santo André, SP, Brasil. Ni: número de indivíduos amostrados; Npar: número de subparcelas de ocorrência; DR: densidade relativa (\%); FR: frequência relativa (\%); DoR: dominância relativa (\%); VI: valor de importância (\%); VC: valor de cobertura (\%).

Table 3. Phytosociological parameters of tree species sampled in P2 plot at the Parque Natural Municipal Nascentes de Paranapiacaba, Santo André, SP, Brazil. Ni: number of individuals sampled; Npar: number of occurrence in the subplots; DR: relative density (\%); FR: relative frequency (\%); DoR: relative dominance (\%); VI: importance value (\%); VC: cover $(\%)$

\begin{tabular}{|c|c|c|c|c|c|c|c|}
\hline Espécies & $\mathrm{Ni}$ & Npar & DR & FR & DoR & VI & $\mathrm{VC}$ \\
\hline Bathysa stipulata (Vell.) C. Presl & 97 & 25 & 12,85 & 5,43 & 7,16 & 25,44 & 20,01 \\
\hline Alchornea triplinervia (Spreng.) Müll. Arg. & 31 & 16 & 4,11 & 3,48 & 11,41 & 18,99 & 15,51 \\
\hline Cyathea delgadii Sternb. & 48 & 18 & 6,36 & 3,91 & 5,06 & 15,33 & 11,42 \\
\hline Guapira opposita (Vell.) Reitz & 40 & 16 & 5,30 & 3,48 & 2,07 & 10,85 & 7,37 \\
\hline Cyathea phalerata Mart. & 30 & 14 & 3,97 & 3,04 & 2,83 & 9,85 & 6,81 \\
\hline Cryptocarya saligna $\mathrm{Mez}$ & 20 & 9 & 2,65 & 1,96 & 3,43 & 8,04 & 6,08 \\
\hline Ocotea elegans $\mathrm{Mez}$ & 13 & 9 & 1,72 & 1,96 & 4,18 & 7,86 & 5,91 \\
\hline Eriotheca pentaphylla (Vell.) A. Robyns & 21 & 12 & 2,78 & 2,61 & 1,68 & 7,07 & 4,46 \\
\hline Guarea macrophylla Vahl & 18 & 11 & 2,38 & 2,39 & 1,95 & 6,73 & 4,34 \\
\hline Croton macrobothris Baill. & 8 & 6 & 1,06 & 1,30 & 4,34 & 6,70 & 5,39 \\
\hline Chrysophyllum inornatum Mart. & 6 & 5 & 0,79 & 1,09 & 4,81 & 6,70 & 5,61 \\
\hline Cabralea canjerana (Vell.) Mart. & 13 & 10 & 1,72 & 2,17 & 2,52 & 6,42 & 4,25 \\
\hline Psychotria nuda (Cham. \& Schltdl.) Wawra & 19 & 10 & 2,52 & 2,17 & 0,59 & 5,28 & 3,11 \\
\hline Ocotea dispersa (Ness) Mez. & 7 & 5 & 0,93 & 1,09 & 3,26 & 5,28 & 4,19 \\
\hline Campomanesia guaviroba (DC.) Kiaersk. & 11 & 8 & 1,46 & 1,74 & 1,81 & 5,00 & 3,27 \\
\hline Chomelia pohliana Müll. Arg. & 14 & 7 & 1,85 & 1,52 & 1,37 & 4,74 & 3,22 \\
\hline Marlierea silvatica (Gardner) Kiaersk. & 6 & 6 & 0,79 & 1,30 & 2,42 & 4,52 & 3,21 \\
\hline Miconia cabucu Hoehne & 7 & 6 & 0,93 & 1,30 & 2,07 & 4,31 & 3,00 \\
\hline Myrcia fallax (Rich.) DC. & 14 & 7 & 1,85 & 1,52 & 0,89 & 4,27 & 2,74 \\
\hline Mouriri chamissoana Cogn. & 11 & 9 & 1,46 & 1,96 & 0,80 & 4,21 & 2,26 \\
\hline Cinnamomum glaziovii (Mez) Kosterm. & 2 & 2 & 0,26 & 0,43 & 3,38 & 4,08 & 3,64 \\
\hline Cryptocarya moschata Nees \& C. Mart. & 5 & 5 & 0,66 & 1,09 & 2,31 & 4,06 & 2,97 \\
\hline Salacia grandifolia (Mart.) G. Don & 16 & 7 & 2,12 & 1,52 & 0,36 & 4,00 & 2,48 \\
\hline Eugenia $\mathrm{cf}$. burkartiana (D. Legrand) D. Legrand & 9 & 7 & 1,19 & 1,52 & 1,11 & 3,82 & 2,30 \\
\hline Mollinedia uleana Perkins & 8 & 6 & 1,06 & 1,30 & 1,40 & 3,77 & 2,46 \\
\hline Eugenia subavenia $\mathrm{O}$. Berg & 12 & 8 & 1,59 & 1,74 & 0,35 & 3,68 & 1,94 \\
\hline Calyptranthes lucida Mart. ex DC. & 10 & 8 & 1,32 & 1,74 & 0,29 & 3,35 & 1,61 \\
\hline Blepharocalyx salicifolius (Kunth) O. Berg & 1 & 1 & 0,13 & 0,22 & 2,90 & 3,25 & 3,04 \\
\hline Psychotria suterella Müll. Arg. & 13 & 5 & 1,72 & 1,09 & 0,34 & 3,14 & 2,06 \\
\hline Chrysophyllum flexuosum Mart. & 9 & 6 & 1,19 & 1,3 & 0,56 & 3,05 & 1,75 \\
\hline Cordia trichoclada DC. & 10 & 6 & 1,32 & 1,3 & 0,39 & 3,01 & 1,71 \\
\hline Myrcia spectabilis DC. & 8 & 7 & 1,06 & 1,52 & 0,42 & 3,00 & 1,48 \\
\hline Alsophila sternbergii (Sternb.) D.S. Conant & 10 & 3 & 1,32 & 0,65 & 0,90 & 2,88 & 2,23 \\
\hline Andira fraxinifolia Benth. & 2 & 2 & 0,26 & 0,43 & 2,06 & 2,76 & 2,33 \\
\hline Calyptranthes grandifolia $\mathrm{O}$. Berg & 5 & 5 & 0,66 & 1,09 & 0,92 & 2,67 & 1,59 \\
\hline Vernonanthura puberula (Less.) H. Rob. & 4 & 3 & 0,53 & 0,65 & 1,47 & 2,65 & 2,00 \\
\hline Hieronima alchorneoides Allemão & 4 & 4 & 0,53 & 0,87 & 1,21 & 2,61 & 1,74 \\
\hline Eugenia neoglomerata Sobral & 7 & 4 & 0,93 & 0,87 & 0,63 & 2,42 & 1,55 \\
\hline Cupania oblongifolia Mart. & 6 & 4 & 0,79 & 0,87 & 0,61 & 2,27 & 1,40 \\
\hline Guatteria elliptica R.E. Fr. & 6 & 5 & 0,79 & 1,09 & 0,19 & 2,07 & 0,98 \\
\hline Tibouchina pulchra (Cham.) Cogn. & 4 & 3 & 0,53 & 0,65 & 0,84 & 2,02 & 1,37 \\
\hline Eugenia pseudomalacantha D. Legrand & 6 & 5 & 0,79 & 1,09 & 0,12 & 2,00 & 0,91 \\
\hline Casearia sylvestris $\mathrm{Sw}$. & 4 & 4 & 0,53 & 0,87 & 0,57 & 1,97 & 1,10 \\
\hline Annona neosericea $\mathrm{H}$. Rainer & 5 & 4 & 0,66 & 0,87 & 0,35 & 1,88 & 1,01 \\
\hline Sloanea monosperma Vell. & 5 & 5 & 0,66 & 1,09 & 0,12 & 1,87 & 0,79 \\
\hline Lauraceae sp.2 & 1 & 1 & 0,13 & 0,22 & 1,46 & 1,81 & 1,60 \\
\hline Coussarea contracta (Walp.) Müll. Arg. & 6 & 4 & 0,79 & 0,87 & 0,10 & 1,77 & 0,90 \\
\hline Matayba juglandifolia Radlk. & 4 & 4 & 0,53 & 0,87 & 0,31 & 1,71 & 0,84 \\
\hline Marlierea excoriata Mart. & 4 & 4 & 0,53 & 0,87 & 0,30 & 1,70 & 0,83 \\
\hline Mollinedia schottiana (Spreng.) Perkins & 5 & 4 & 0,66 & 0,87 & 0,16 & 1,69 & 0,82 \\
\hline Bactris setosa Mart. & 5 & 4 & 0,66 & 0,87 & 0,07 & 1,60 & 0,73 \\
\hline
\end{tabular}


Tabela 3 (continuação)

\begin{tabular}{|c|c|c|c|c|c|c|c|}
\hline Espécies & $\mathrm{Ni}$ & Npar & DR & FR & DoR & VI & $\mathrm{VC}$ \\
\hline Calyptranthes fusiformis M.L. Kawas. & 4 & 4 & 0,53 & 0,87 & 0,16 & 1,56 & 0,69 \\
\hline Rapanea umbellata (Mart.) Mez & 4 & 2 & 0,53 & 0,43 & 0,52 & 1,48 & 1,05 \\
\hline Heisteria silvianii Schwacke & 3 & 3 & 0,40 & 0,65 & 0,37 & 1,42 & 0,77 \\
\hline Euplassa hoehnei Sleumer & 4 & 3 & 0,53 & 0,65 & 0,19 & 1,37 & 0,72 \\
\hline Schefflera angustissima (Marchal) Frodin & 4 & 3 & 0,53 & 0,65 & 0,19 & 1,37 & 0,72 \\
\hline Myrciaria floribunda (H. West ex Willd.) O. Berg & 4 & 3 & 0,53 & 0,65 & 0,12 & 1,30 & 0,65 \\
\hline Critoniopsis quinqueflora (Less.) H. Rob. & 1 & 1 & 0,13 & 0,22 & 0,86 & 1,21 & 0,99 \\
\hline Cryptocarya aschersoniana $\mathrm{Mez}$ & 3 & 2 & 0,40 & 0,43 & 0,32 & 1,15 & 0,71 \\
\hline Gomidesia tijucensis (Kiaersk.) D. Legrand & 3 & 3 & 0,40 & 0,65 & 0,07 & 1,12 & 0,47 \\
\hline Eugenia stictosepala Kiaersk. & 3 & 3 & 0,40 & 0,65 & 0,06 & 1,11 & 0,46 \\
\hline Rudgea jasminoides (Cham.) Müll. Arg. & 3 & 3 & 0,40 & 0,65 & 0,05 & 1,10 & 0,44 \\
\hline Eugenia cf. malacantha D. Legrand & 2 & 2 & 0,26 & 0,43 & 0,39 & 1,09 & 0,66 \\
\hline Inga sessilis (Vell.) Mart. & 2 & 2 & 0,26 & 0,43 & 0,39 & 1,09 & 0,66 \\
\hline Myrceugenia myrcioides (Cambess.) O. Berg & 3 & 3 & 0,40 & 0,65 & 0,04 & 1,09 & 0,44 \\
\hline Alsophila setosa Kaulf. & 4 & 2 & 0,53 & 0,43 & 0,10 & 1,06 & 0,63 \\
\hline Cecropia pachystachya Trécul & 2 & 2 & 0,26 & 0,43 & 0,28 & 0,98 & 0,54 \\
\hline Sapium glandulosum (L.) Morong & 2 & 2 & 0,26 & 0,43 & 0,26 & 0,96 & 0,52 \\
\hline Cupania furfuracea Radlk. & 2 & 1 & 0,26 & 0,22 & 0,46 & 0,95 & 0,73 \\
\hline Eugenia cerasiflora Miq. & 3 & 2 & 0,40 & 0,43 & 0,08 & 0,91 & 0,47 \\
\hline Alseis floribunda Schott & 2 & 2 & 0,26 & 0,43 & 0,18 & 0,88 & 0,45 \\
\hline Solanum cinnamomeum Sendtn. & 1 & 1 & 0,13 & 0,22 & 0,45 & 0,80 & 0,58 \\
\hline Ocotea paranapiacabensis Coe-Teixeira & 2 & 2 & 0,26 & 0,43 & 0,06 & 0,76 & 0,32 \\
\hline Guapira nitida (Schmidt) Lundell & 2 & 2 & 0,26 & 0,43 & 0,04 & 0,74 & 0,31 \\
\hline Faramea tetragona Müll. Arg. & 2 & 2 & 0,26 & 0,43 & 0,04 & 0,74 & 0,30 \\
\hline Myrceugenia miersiana (Gardner) D. Legrand \& Kausel & 2 & 2 & 0,26 & 0,43 & 0,04 & 0,73 & 0,30 \\
\hline Allophylus petiolulatus Radlk. & 2 & 2 & 0,26 & 0,43 & 0,03 & 0,73 & 0,30 \\
\hline Rapanea hermogenesii Jung-Mend. \& Bernacci & 2 & 2 & 0,26 & 0,43 & 0,03 & 0,73 & 0,30 \\
\hline Mollinedia triflora (Spreng.) Tul. & 2 & 2 & 0,26 & 0,43 & 0,03 & 0,73 & 0,29 \\
\hline Ouratea multiflora (A. St.-Hil.) Engl. & 2 & 2 & 0,26 & 0,43 & 0,03 & 0,73 & 0,29 \\
\hline Myrcia tijucensis Kiaersk. & 3 & 1 & 0,40 & 0,22 & 0,05 & 0,67 & 0,45 \\
\hline Aegiphila sellowiana Cham. & 1 & 1 & 0,13 & 0,22 & 0,29 & 0,64 & 0,42 \\
\hline Indeterminada 2 & 1 & 1 & 0,13 & 0,22 & 0,28 & 0,63 & 0,42 \\
\hline Coccoloba glaziovii Lindau & 1 & 1 & 0,13 & 0,22 & 0,26 & 0,61 & 0,39 \\
\hline Ocotea pulchella (Nees) Mez & 2 & 1 & 0,26 & 0,22 & 0,11 & 0,59 & 0,37 \\
\hline Rapanea ferruginea (Ruiz \& Pav.) Mez & 1 & 1 & 0,13 & 0,22 & 0,22 & 0,57 & 0,35 \\
\hline Ocotea brachybotrya (Meisn.) Mez & 2 & 1 & 0,26 & 0,22 & 0,04 & 0,52 & 0,30 \\
\hline Senna multijuga (Rich.) H.S. Irwin \& Barneby & 1 & 1 & 0,13 & 0,22 & 0,17 & 0,52 & 0,30 \\
\hline Myrcia pubipetala Miq. & 1 & 1 & 0,13 & 0,22 & 0,17 & 0,52 & 0,30 \\
\hline Aspidosperma olivaceum Müll. Arg. & 1 & 1 & 0,13 & 0,22 & 0,15 & 0,50 & 0,28 \\
\hline Myrtaceae sp.6 & 1 & 1 & 0,13 & 0,22 & 0,14 & 0,49 & 0,27 \\
\hline Ocotea glaziovii $\mathrm{Mez}$ & 1 & 1 & 0,13 & 0,22 & 0,12 & 0,47 & 0,25 \\
\hline Ecclinusa ramiflora Mart. & 1 & 1 & 0,13 & 0,22 & 0,11 & 0,46 & 0,24 \\
\hline Myrcia cf. richardiana (O.Berg) Kiaersk. & 1 & 1 & 0,13 & 0,22 & 0,10 & 0,45 & 0,23 \\
\hline Eugenia sp.1 & 1 & 1 & 0,13 & 0,22 & 0,08 & 0,43 & 0,21 \\
\hline Solanum rufescens Sendtn. & 1 & 1 & 0,13 & 0,22 & 0,08 & 0,43 & 0,21 \\
\hline Neomitranthes cf. amblymitra (Burret) Mattos & 1 & 1 & 0,13 & 0,22 & 0,08 & 0,43 & 0,21 \\
\hline Cordia sellowiana Cham. & 1 & 1 & 0,13 & 0,22 & 0,07 & 0,42 & 0,20 \\
\hline Schoepfia brasiliensis A. DC. & 1 & 1 & 0,13 & 0,22 & 0,07 & 0,42 & 0,20 \\
\hline Myrtaceae sp.5 & 1 & 1 & 0,13 & 0,22 & 0,06 & 0,41 & 0,19 \\
\hline Miconia tristis Spring & 1 & 1 & 0,13 & 0,22 & 0,05 & 0,40 & 0,18 \\
\hline Prunus myrtifolia (L.) Urb. & 1 & 1 & 0,13 & 0,22 & 0,05 & 0,40 & 0,18 \\
\hline Eugenia mosenii (Kausel) Sobral & 1 & 1 & 0,13 & 0,22 & 0,05 & 0,40 & 0,18 \\
\hline Pouteria cf. bullata (S. Moore) Baehni & 1 & 1 & 0,13 & 0,22 & 0,04 & 0,39 & 0,17 \\
\hline Miconia discolor DC. & 1 & 1 & 0,13 & 0,22 & 0,04 & 0,39 & 0,17 \\
\hline Piptadenia paniculata Benth. & 1 & 1 & 0,13 & 0,22 & 0,03 & 0,38 & 0,17 \\
\hline Myrcia bicarinata (O. Berg) D. Legrand & 1 & 1 & 0,13 & 0,22 & 0,03 & 0,38 & 0,17 \\
\hline
\end{tabular}


Tabela 3 (continuação)

\begin{tabular}{|c|c|c|c|c|c|c|c|}
\hline Espécies & $\mathrm{Ni}$ & Npar & DR & FR & DoR & VI & $\mathrm{VC}$ \\
\hline Dendropanax heterophyllus (Marchal) Frodin & 1 & 1 & 0,13 & 0,22 & 0,03 & 0,38 & 0,16 \\
\hline Myrtaceae sp. 3 & 1 & 1 & 0,13 & 0,22 & 0,03 & 0,38 & 0,16 \\
\hline Ocotea teleiandra (Meisn.) $\mathrm{Mez}$ & 1 & 1 & 0,13 & 0,22 & 0,03 & 0,38 & 0,16 \\
\hline Zollernia ilicifolia (Brongn.) Vogel & 1 & 1 & 0,13 & 0,22 & 0,03 & 0,38 & 0,16 \\
\hline Citronella paniculata (Mart.) R.A. Howard & 1 & 1 & 0,13 & 0,22 & 0,02 & 0,37 & 0,16 \\
\hline Euterpe edulis Mart. & 1 & 1 & 0,13 & 0,22 & 0,02 & 0,37 & 0,16 \\
\hline Myrtaceae sp.4 & 1 & 1 & 0,13 & 0,22 & 0,02 & 0,37 & 0,16 \\
\hline Ocotea laxa (Nees) Mez & 1 & 1 & 0,13 & 0,22 & 0,02 & 0,37 & 0,16 \\
\hline Indeterminada 1 & 1 & 1 & 0,13 & 0,22 & 0,02 & 0,37 & 0,16 \\
\hline Eugenia bocainensis Mattos & 1 & 1 & 0,13 & 0,22 & 0,02 & 0,37 & 0,15 \\
\hline Gordonia fruticosa (Schrad.) H. Keng & 1 & 1 & 0,13 & 0,22 & 0,02 & 0,37 & 0,15 \\
\hline Cyathea dichromatolepis (Fée) Domin & 1 & 1 & 0,13 & 0,22 & 0,02 & 0,37 & 0,15 \\
\hline Lauraceae sp.1 & 1 & 1 & 0,13 & 0,22 & 0,02 & 0,37 & 0,15 \\
\hline Amaioua intermedia Mart. & 1 & 1 & 0,13 & 0,22 & 0,02 & 0,36 & 0,15 \\
\hline Erythroxylum cuspidifolium Mart. & 1 & 1 & 0,13 & 0,22 & 0,02 & 0,36 & 0,15 \\
\hline Chionanthus filiformis (Vell.) P.S. Green & 1 & 1 & 0,13 & 0,22 & 0,01 & 0,36 & 0,15 \\
\hline Xylopia langsdorfiana A.St.-Hil. \& Tulasne & 1 & 1 & 0,13 & 0,22 & 0,01 & 0,36 & 0,15 \\
\hline Quararibea turbinata (Sw.) Poir. & 1 & 1 & 0,13 & 0,22 & 0,01 & 0,36 & 0,14 \\
\hline Gomidesia flagellaris D. Legrand & 1 & 1 & 0,13 & 0,22 & 0,01 & 0,36 & 0,14 \\
\hline Total & 755 & 460 & 100,00 & 100,00 & 100,00 & 300,00 & 200,00 \\
\hline
\end{tabular}

Tabela 4. Média do número de indivíduos amostrados nas parcelas P1 e P2 por categoria sucessional e síndromes de dispersão, com as respectivas porcentagens e desvios padrões, no Parque Natural Municipal Nascentes de Paranapiacaba, Santo André, SP, Brasil. Ni: número total de indivíduos amostrados; P: espécies pioneiras; NP: não pioneiras; NC: espécie não caracterizada; ANE: anemocórica; ZOO: zoocórica.

Table 4. Average number of individuals sampled from plots P1 and P2 by successional category and dispersal syndromes, with respective percentages and standard deviations at the Parque Natural Municipal Nascentes de Paranapiacaba, Santo André, São Paulo State, Brazil. Ni: Total number of individuals sampled; P: pioneer species; NP: non-pioneer; NC: not characterized species; ANE: anemochoric, ZOO: zoochoric.

\begin{tabular}{rcccccc}
\hline Parcelas & Ni & P & NP & NC & ANE & ZOO \\
\hline P1 & \multirow{2}{*}{1.237} & $41,88 \pm 9,46$ & $27,96 \pm 13,12$ & $5,00 \pm 3,96$ & $9,24 \pm 7,75$ & $40,16 \pm 19,00$ \\
\%1 & & $40,99 \pm 9,16$ & $47,05 \pm 12,82$ & $11,72 \pm 3,71$ & $17,78 \pm 7,48$ & $78,58 \pm 18,43$ \\
P2 & 755 & $10,90 \pm 4,50$ & $17,32 \pm 8,40$ & $1,72 \pm 1,31$ & $9,24 \pm 4,93$ & $20,64 \pm 8,62$ \\
$\%$ P2 & & $36,46 \pm 4,46$ & $57,48 \pm 8,50$ & $5,96 \pm 1,32$ & $13,38 \pm 4,98$ & $81,06 \pm 8,50$ \\
\hline
\end{tabular}

e Lauraceae, resultado semelhante ao obtido em florestas baixo-montanas (700-1.100 m) do Sudeste do Brasil (Oliveira Filho \& Fontes 2000, Tabarelli \& Mantovani 1999). No Estado de São Paulo, diferentes trabalhos também mostram o predomínio de espécies de Myrtaceae, como na Juréia (Mamede et al. 2004, Melo et al. 2000), na Ilha do Cardoso (Melo \& Mantovani 1994) e na Reserva do Morro Grande (Catharino et al. 2006). O contrário ocorre em áreas perturbadas de Cubatão e Paranapiacaba, onde as famílias Melastomataceae e Fabaceae predominam em relação a Myrtaceae, indicando estágio sucessional inicial (Leitão Filho 1993, Pompéia 1997, Sugiyama et al. 2009).

Na parcela P1, Melastomataceae é a família mais importante devido ao alto VI de Miconia cabucu e Tibouchina pulchra, duas espécies pioneiras. O mesmo valor de importância foi obtido para essa família nas áreas da Reserva Biológica Alto da Serra de Paranapiacaba (Sugiyama et al. 2009), vale do rio Mogi (Leitão Filho 1993), vale do rio Mogi, vale do rio Pilões e Caminhos do Mar (Pompéia 1997). Por outro lado, na Estação Ecológica Juréia-Itatins (Mamede et al. 2004), a família Myrtaceae apresentou o maior 


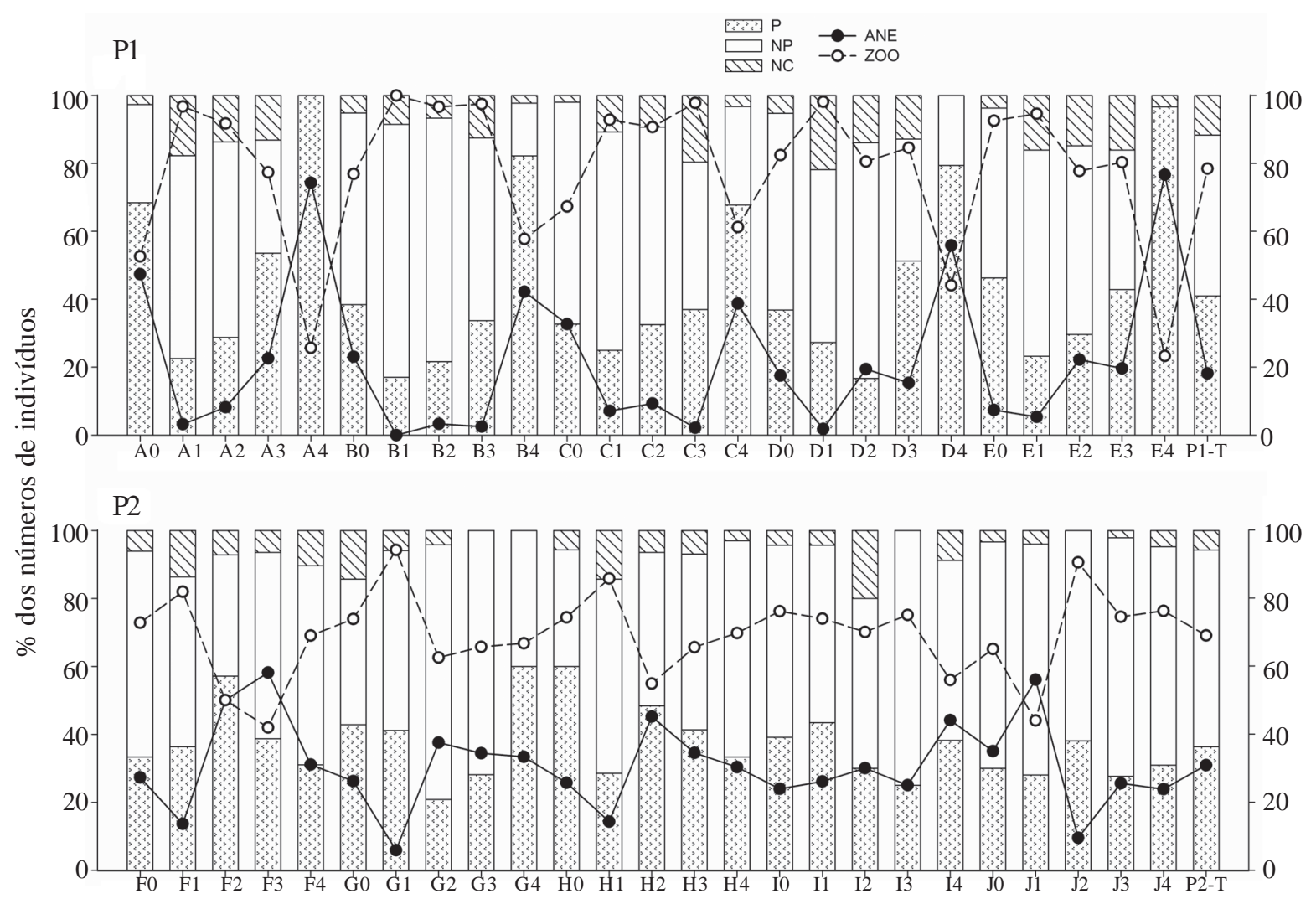

Figura 3. Porcentagem de indivíduos nas subparcelas de P1 e P2, de acordo com as categorias sucessionais e síndromes de dispersão. P: pioneiras "sensu lato"; NP: não pioneiras; NC: não caracterizada; ANE: anemocórica; ZOO: zoocórica P1-T: Porcentagem total de indivíduos de P1; P2-T: Porcentagem total de indivíduos de P2.

Figure 3. Percentage of individuals in the subplots of P1 and P2 according to the guilds and dispersal syndromes. P: pioneer; NP: non-pioneer; NC: not characterized; ANE: anemocoric; ZOO: zoochoric; P1-T: total percentage of individuals in the plot P1; P2-T: total percentage of individuals in $\mathrm{P} 2$.

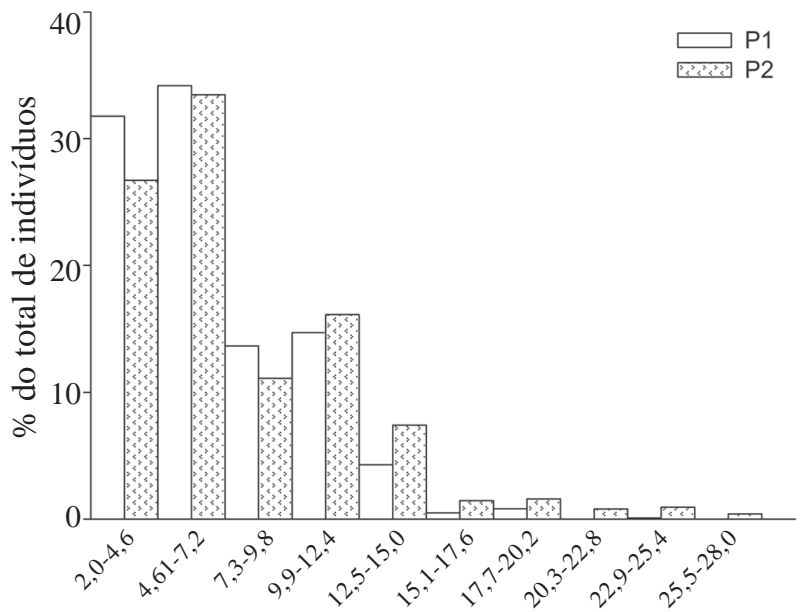

Classes de altura $(\mathrm{m})$

Figura 4. Frequência das classes de altura das árvores amostradas nas parcelas P1 e P2.

Figure 4. Frequency of height classes from trees sampled in P1 and $\mathrm{P} 2$ plots.

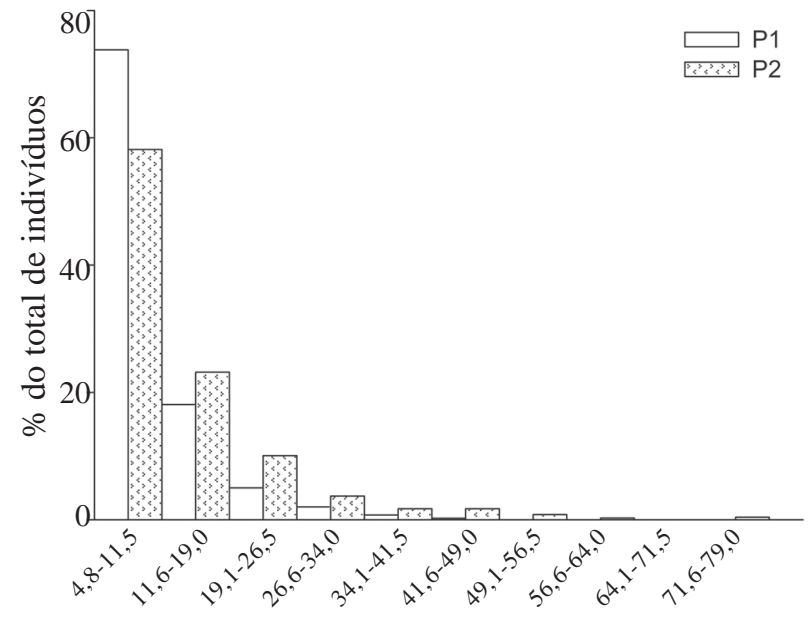

Classes de DAP $(\mathrm{cm})$

Figura 5. Frequência das classes de diâmetro das árvores amostradas nas parcelas P1 e P2.

Figure 5. Frequency of diameter classes from trees sampled in P1 and $\mathrm{P} 2$ plots. 


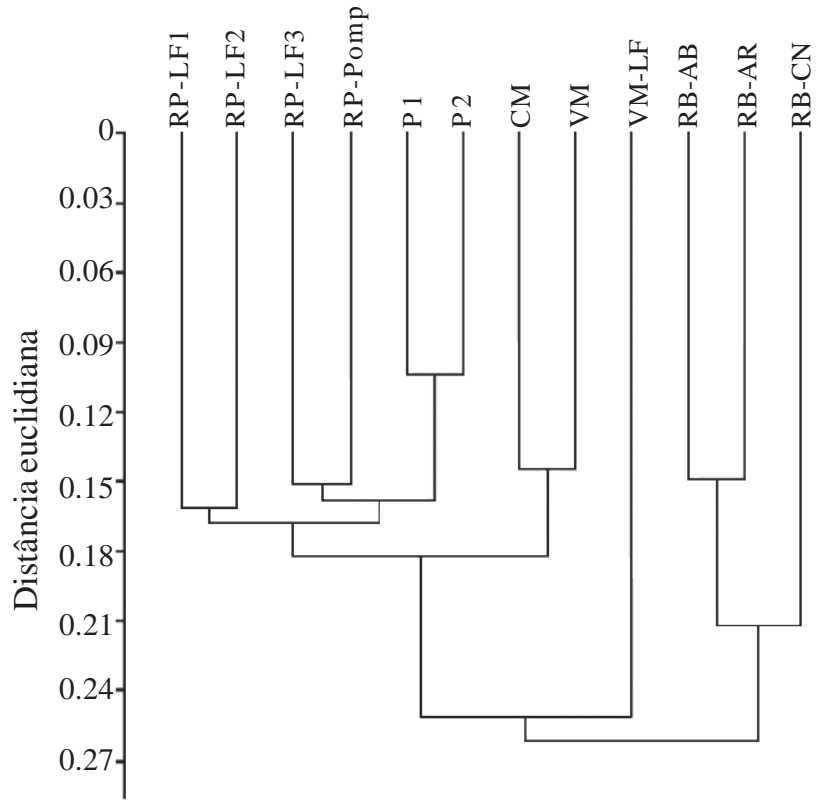

Figura 6. Dendrograma da análise de agrupamento com base nos dados de abundância obtidos de trabalhos realizados na região da Serra do Mar sob a influência dos poluentes de Cubatão. Os códigos das áreas comparadas são os mesmos utilizados na figura 1 e tabela 5 .

Figure 6. Dendrogram of the cluster analysis based on the abundance data from reports of different areas in the Serra do Mar, under influence of Cubatão's pollutants from. The codes of compared areas are the same in figure 1 and table 5 .

valor de riqueza e abundância. Guapira opposita também apresentou alto VI em P1, principalmente pela densidade, o dobro de Miconia cabucu, que apresentou o maior VI. Em P2 Guapira opposita também apresentou alto VI, mas principalmente pela dominância. À semelhança do PNMNP, Pompéia (1997) também aponta o alto VI de Guapira opposita no vale do rio Pilões, principalmente pela dominância numérica.

Os impactos da poluição atmosférica do complexo industrial de Cubatão refletem-se na redução da diversidade, principalmente nas áreas do vale do rio Mogi (Leitão Filho 1993, Pompéia 1997) e na Reserva Biológica Alto da Serra de Paranapiacaba, referida de agora em diante como RB (Sugiyama et al. 2009), enquanto que áreas mais abrigadas, como o vale do rio Pilões e Caminho do Mar, apresentaram maiores valores de diversidade (Leitão Filho 1993, Pompéia 1997, Sugiyama et al. 2009).

Os valores de diversidade obtidos no PNMNP, tanto para P1 quanto para P2, asselham-se ao de áreas preservadas há mais tempo, como é o caso da Juréia, Ilha do Cardoso, Reserva de Morro Grande e Santa
Virgínia, esta última com histórico documentado da recuperação com mais de 40 anos (Catharino et al. 2006, Melo \& Mantovani 1994, Melo et al. 2000, Tabarelli \& Mantovani 1999).

$\mathrm{O}$ valor obtido para a diversidade das parcelas $\mathrm{P} 1$ e P2 assemelha-se a de outros trabalhos realizados em áreas cuja recuperação já ocorre entre 60 e 80 anos (Brown \& Lugo 1990, Saldarriaga \& Uhl 1991, Tabarelli \& Mantovani 1999) apresentando valores similares a florestas maduras.

Os altos valores de diversidade encontrados em $\mathrm{P} 1$ e P2 indicam que a área do PNMNP certamente não foi influenciada pelas correntes atmosféricas advindas do complexo industrial de Cubatão, através do Vale do Rio Mogi, da mesma forma que a RB (Sugiyama et al. 2009) e o vale do rio Mogi (Leitão Filho 1993, Pompéia 1997).

Em relação ao índice de equabilidade (J'), os resultados das parcelas $\mathrm{P} 1$ e $\mathrm{P} 2$ também assemelhamse àqueles obtidos no vale do rio Pilões, Juréia, Ilha do Cardoso e Morro Grande. Além disso, há maior uniformidade na distribuição dos indivíduos entre as espécies, principalmente da parcela P2, quando comparada com as áreas da Reserva Biológica, $\mathrm{RB}-\mathrm{AB}$ e RB-AR, que apresentam os menores valores de equabilidade (tabela 5 ).

Cabe ressaltar, entretanto, que a comparação da diversidade em diferentes áreas pode ser problemática, seja pelas distintas metodologias utilizadas (quadrantes ou parcelas), diferentes critérios de inclusão, diferentes tamanhos das áreas amostradas ou histórico de degradação.

As parcelas P1 e P2 possuem histórico de perturbação distinto. Em P1 um indício da perturbação recente é a presença de Melimis mimutiflora P. Beauv. (capim-gordura). e uma condição sucessional mais inicial na extremidade sudoeste, verificada pelo predomínio de espécies pioneiras nas sub-parcelas A4, B4, C4, D4 e E4 (figura 3). As espécies que representam esta sucessão inicial em P1 são: Baccharis oreophylla, Piptocarpha axillaris, Vernonanthura puberula (Asteraceae), Tibouchina pulchra, Miconia cabucu (Melastomataceae) e Clethra scabra (Clethraceae) (tabela 1). Segundo Tabarelli et al. (1999), a presença abundante de espécies dos gêneros Tibouchina e Miconia é indicadora dos estágios iniciais de sucessão nas florestas da encosta atlântica.

Por outro lado, comparando as parcelas P1 e P2 entre si, observamos que não existem diferenças entre 


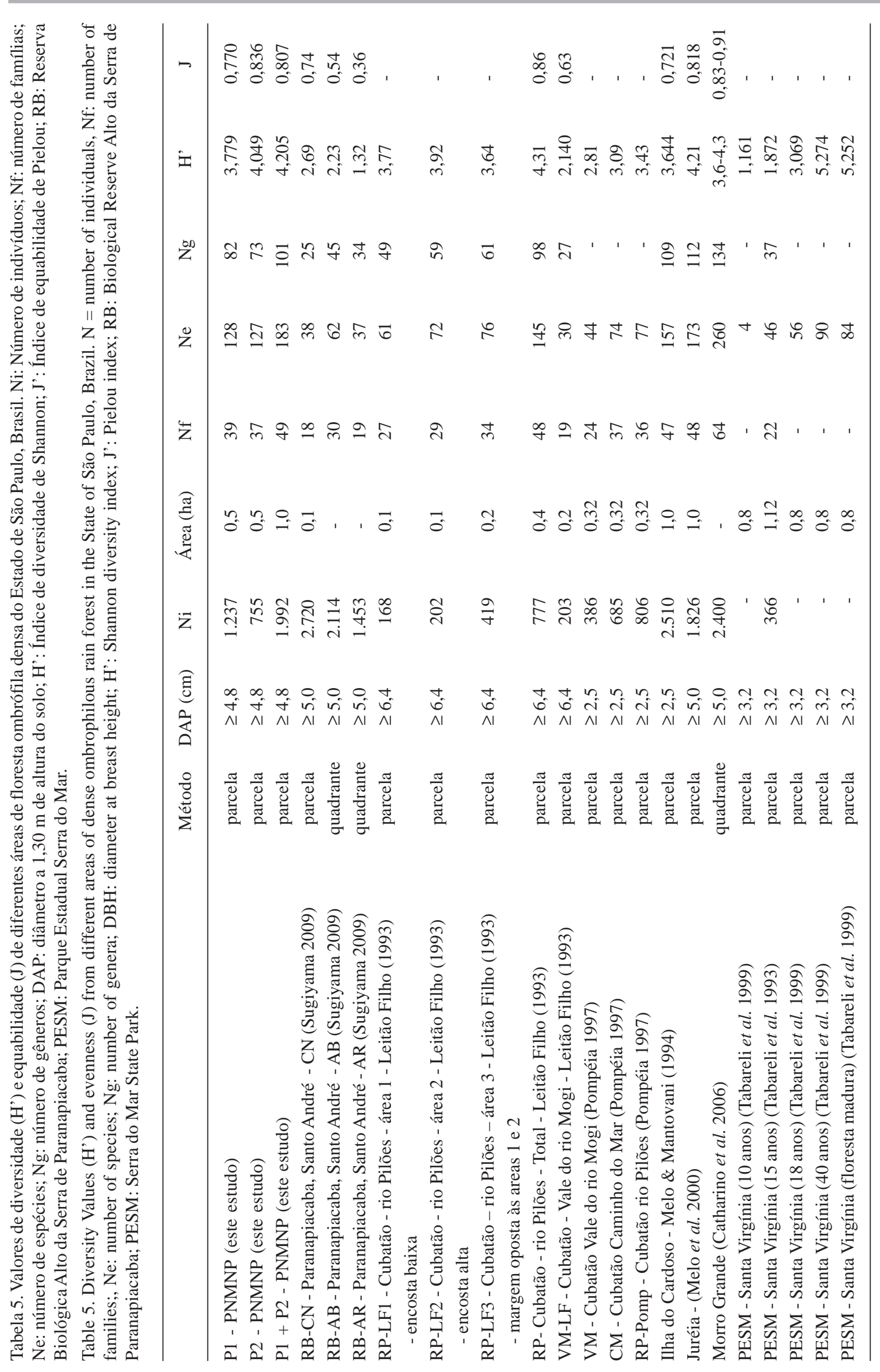


as médias da porcentagem do número de indivíduos nas duas parcelas em relação às categorias sucessionais (tabela 4 , figura 3 ).

Apesar do predomínio de espécies zoocóricas, essa distribuição não é uniforme em relação a todas as sub-parcelas (tabela 1, figura 3). Um conjunto de sub-parcelas situadas na extremidade sudoeste da parcela P1 apresentou maior proporção de espécies anemocóricas e pioneiras (A4, D4, E4), assim como as sub-parcelas F3 e J1 em P2. Essa extremidade da parcela P1 possui a condição sucessional mais inicial, com uma borda desmatada, além disso, há também grande quantidade de indivíduos mortos em pé, representados principalmente por espécies pioneiras de ciclo de vida curto, cerca de $15 \%$ da amostragem. Situação semelhante é descrita por Leitão Filho (1993) e Pompéia (1997) na área do vale do rio Pilões, que mencionam ser essa uma condição esperada para áreas em recuperação.

Nas florestas tropicais de climas úmidos ou com pequena estacionalidade pluvial, a zoocoria é mais freqüente (Howe \& Smallwood 1982, van der Pijl 1982), enquanto a anemocoria predomina em ambientes mais abertos, secos e na borda de fragmentos (Howe \& Smallwood 1982, Tabarelli et al. 1999, Yamamoto et al. 2005).

À medida que aumenta a idade de uma floresta, aumenta também a proporção de espécies zoocóricas e, segundo o modelo utilizado por Liebsch et al. (2008), seriam necessários aproximadamente 65 anos para que uma floresta atingisse a proporção de $80 \%$ de espécies zoocóricas, demonstrando que em relação à síndrome de dispersão, o tempo de recuperação é relativamente curto. Verificamos que nas duas parcelas a proporção de espécies zoocóricas está muito próxima desse patamar, sendo 77,67 $\pm 22,19 \%$ e $69,16 \pm 12,86 \%$ para P1 e P2, respectivamente. Ainda segundo Pompéia (2006), espécies zoocóricas necessitam de dispersores especializados e são características de estágios sucessionais não pioneiros.

A densidade duas vezes maior de $\mathrm{P} 1$ em relação a P2 é devida ao maior número de árvores nas classes de menor diâmetro. Normalmente as comunidades em equilíbrio apresentam histogramas de freqüência de classes de diâmetro como uma série geométrica decrescente (Martins 1991), porém, se há grande concentração nas classes menores, é um indicativo de que boa parte das populações das espécies arbóreas está em crescimento e é constituída por árvores jovens, como é o caso de P1. Na estratificação vertical das parcelas $\mathrm{P} 1$ e $\mathrm{P} 2$ há maior número de indivíduos nas classes menores de alturas e diâmetros (figuras 4,5).

Em P1 o grande número de indivíduos em baixas classes de diâmetro e altura deve-se às populações de Guapira opposita e Psychotria suterella, espécies de pequeno porte e diâmetro reduzido, típicas do sub-bosque, além de duas espécies heliófilas pioneiras bem representadas principalmente na região da borda, Baccharis oreophylla e Hedyosmum brasiliense. Por outro lado, em P2 também há várias espécies responsáveis pelas classes mais baixas de diâmetro e altura, como Bathysa stipulata, Guapira opposita, Psychotria suterella, Psychotria nuda, Salacia grandifolia e várias espécies de Myrtaceae e Lauraceae, com muitos indivíduos jovens que ainda não atingiram o dossel, como Myrcia fallax e Ocotea paranapiacabensis.

Num contexto geral, são consideradas florestas maduras aquelas onde existe maior número de árvores com grandes valores de área basal, enquanto que aquelas em estágios mais iniciais de sucessão possuiriam grande número de árvores com troncos finos (Parthasarathy 1999).

Trabalhos realizados em UCs do Estado de São Paulo, como o Parque Estadual da Ilha do Cardoso (Melo \& Mantovani 1994) e a Estação Ecológica Juréia-Itatins (Melo at al.), apontam Euterpe edulis como a espécie de maior VI e, mesmo na RB, Sugiyama (2009) referiu sua grande representatividade numérica. Esse fato mostra a importância de uma UC na manutenção da biodiversidade. No PNMNP, uma UC criada recentemente, o intenso extrativismo de palmito ocasionou praticamente a extinção local dessa espécie, representada na área estudada por um único indivíduo.

Apesar da diferença dos resultados obtidos em $\mathrm{P} 1$ e P2, verificamos que nos fragmentos estudados predominam espécies de ampla distribuição como Alchornea triplinervia, Guapira opposita, Psychotria suterella, Miconia cabucu, Bathysa stipulata e Tibouchina pulchra entre outras. Segundo Liebsch et al. (2008), florestas consideradas mais jovens apresentam abundância de espécies com ampla distribuição geográfica.

A análise de agrupamento a partir dos trabalhos realizados na região de Cubatão revelou a clara situação de isolamento da $\mathrm{RB}$, ainda mais acentuada pela baixa diversidade específica obtida na área (Sugiyama 2009) em relação às demais. A mesma situação é observada no vale do rio Mogi VM-LF, 
que também apresenta diversidade específica baixa, com sinais evidentes da situação de degradação por poluentes atmosféricos de Cubatão (Leitão Filho 1993). Como P1 e P2 formaram um agrupamento com as áreas estudadas no vale do rio Pilões, que possuem maior diversidade, fica evidente a situação mais preservada dessas parcelas em relação às demais áreas analisadas (tabela 5, figura 6).

As parcelas amostradas são parte da floresta secundária resultante principalmente do corte seletivo da floresta original iniciado em 1860, para a manutenção da ferrovia Santos-Jundiaí, bem como de antigas pastagens abandonadas a partir da década de 1980. Essas duas modalidades de perturbação refletem-se nos parâmetros fitossociológicos das parcelas, principalmente na concentração de indivíduos em classes inferiores de altura e diâmetro, bem como na florística, onde espécies pioneiras de ampla distribuição geográfica dominam sua composição.

Situação diversa é encontrada na RB, que apesar de ser uma UC desde o início do século XX, não escapou aos efeitos deletérios dos poluentes atmosféricos ocorridos desde a década de 1950, e da extração predatória de palmito juçara, Euterpe edulis Mart., nos anos de 1990 (Jordão \& Poggiani 2009). Esses impactos são verificados através da análise da estrutura da floresta que apresenta os menores valores de diversidade para a Mata Atlântica secundária da Serra do Mar no Estado de São Paulo (tabela 5).

A estrutura das florestas secundárias também é influenciada pela topografia, por exemplo, na maior abundância de espécies pioneiras em relevos mais íngremes (Bianchini et al. 2010).

Estudos realizados em 10 parcelas de florestas tropicais com diferentes gradientes topográficos revelaram que a inclinação não influencia a densidade ou a área basal de árvores, principalmente do dossel (Losos 2004). Além disso, nas florestas tropicais, pequenos gradientes altitudinais não são capazes de influenciar os parâmetros fitossociológicos (Lieberman et al. 1996, Meireles et al. 2008).

Na RB, Sugiyama (2009) relacionou às condições topográficas e climáticas do topo da Serra, como terreno fortemente inclinado, exposto aos ventos e à maior incidência luminosa, a ocorrência de florestas aparentemente em estágios iniciais de sucessão, mas que não teriam condições de evoluir para outros estágios.

Apesar das parcelas P1 e P2 possuírem topografia distinta, principalmente em $\mathrm{P} 2$, onde o desnível entre pontos pode chegar a $40 \mathrm{~m}$, aparentemente essa variação não influenciou na distribuição das espécies nas parcelas, uma vez que não há concentração de espécies pioneiras nas subparcelas mais íngremes.

Pela ocorrência de indivíduos de grande porte de espécies não pioneiras como Blepharocalyx salicifolius $(\mathrm{DAP}=78,9 \mathrm{~cm})$, Ocotea dispersa $(\mathrm{DAP}=75,0 \mathrm{~cm})$ e Cinnamomum glaziovii $(\mathrm{DAP}=61,1)$, a parcela $\mathrm{P} 2$ parece ser um pequeno relicto mais preservado da floresta original que recobria a região. Entretanto, os parâmetros fitossociológicos indicam que as parcelas P1 e P2 são semelhantes do ponto de vista das categorias sucessionais ou síndromes de dispersão. Não existe diferença entre a distribuição de espécies pioneiras e não pioneiras e nem em relação às síndromes, sendo a zoocoria predominante sobre a anemocoria em ambas, com exceção das subparcelas da borda de P1, que se encontram em estágio inicial de sucessão, com predomínio de espécies pioneiras.

Com relação à diversidade, observa-se que os valores encontrados para P1 e P2 aproximam-se daqueles obtidos em UCs mais antigas como a Juréia e Ilha do Cardoso, sem histórico de perturbação recente. Além disso, na análise de agrupamento, as parcelas P1 e P2 aparecem juntas àquelas estudadas no vale do rio Pilões, uma das áreas menos impactadas pela poluição de Cubatão. Com base nesses resultados, fica aparente através da florística e estrutura dos trechos amostrados no PNMNP, que fatores como corte raso para formação de pastagem em P1 e corte seletivo de espécies arbóreas em P2 foram mais importantes na formação da floresta secundária do que a poluição atmosférica do Complexo Industrial de Cubatão, se comparada com as áreas do vale do rio Mogi ou da RB, com suas matas altamente depauperadas.

\section{Agradecimentos}

À Secretaria de Gestão de Recursos Naturais de Paranapiacaba e Parque Andreense, pelas autorizações concedidas para realização do presente trabalho. Ao Centro Universitário Fundação Santo André, pela permissão de uso das instalações do Centro de Estudos e Formação Sócioambiental (CEFS) de Paranapiacaba. Ao programa Biota-FAPESP pelo auxílio concedido para implantação das parcelas permanentes através do projeto "Flora Aromática da Mata Atlântica". Ao CNPq pela bolsa de estudo 
concedida ao primeiro autor.

\section{Literatura citada}

ACIESP. 1997. Glossário de Ecologia. Academia de Ciências do Estado de São Paulo, São Paulo.

APG III. 2009. An update of the Angiosperm Phylogeny Group classification for the orders and families of flowering plants: APG III. Botanical Journal of the Linnean Society 161: 105-121.

Aubreville, A. 1938. La forêt coloniale: les forêts de l'Afrique occidentale française. Academie des Sciences Coloniales: Annales 9: 126-137.

Bianchini, E., Garcia, C.C., Pimenta, J.A. \& Toreza, J.M.D. 2010. Slope variation and population structure of tree species from different ecological groups in South Brazil. Anais da Academia Brasileira de Ciências 82: 643-652.

Brown, S. \& Lugo, A.E. 1990. Tropical secundary forests. Journal of Tropical Ecology 6: 1-32.

Budowski, G. 1965. Distribution of tropical American rain Forest species in the light of sucessional processes. Turrialba 15: 40-42.

Burslem, D.F.R. \& Swaine, M.D. 2002. Forest Dynamics and Regeneration. In: Robin L. Chazdon \& Timothy Charles Whitmore (eds.). Fundations of Tropical Forest Biology. Classic Papers with Commentaries. University of Chicago Press, Chicago, pp. 577-583.

Catharino,E.L.M.,Bernacci,L.C.,Franco,GA.D.C.,Durigan,G. \& Metzger, J.P. 2006. Aspectos da composição e diversidade do componente arbóreo das florestas da Reserva Florestal do Morro Grande, Cotia, SP. Biota Neotropica 6: http://www.biotaneotropica.org.br/v6n2/pt/ abstract?article+bn00306022006 (acesso em 15.07.2008).

Chazdon, R.L. 2008. Chance and determinism in tropical forest succession. In: W.P. Carson \& S.A. Schnitzer (eds.). Tropical forest community ecology. WileyBlackwell, Oxford, pp. 384-408.

Creed, J.C. 2006. Perturbações em comunidades biológicas. In: C.F.D. Rocha, H.G. Bergallo, M.V. Sluys \& M.A.S. Alves (eds.). Biologia da Conservação: Essências. RiMa, São Carlos, pp. 183-209.

Felfili, J.M. \& Rezende, R.P. 2003. Conceitos e métodos em fitossociologia. Universidade de Brasilia, Brasília.

Felfili, J.M. \& Fagg, C.W. 2007. Floristic composition, diversity and structure of the "cerrado" sensu stricto on rocky soils in northern Goiás and southern Tocantins, Brazil. Revista Brasileira de Botânica 30: 375-385.

Fernandes, I. 1997. Taxonomia e fitogeografia de Cyatheaceae e Dicksoniaceae nas Regiões Sul e Sudeste do Brasil. Tese de Doutorado. Universidade de São Paulo, São Paulo.

Fidalgo, O. \& Bononi, V.L.R. 1989. Técnicas de coleta, preservação e herborização de material botânico. Instituto de Botânica, São Paulo.

Fonseca, R.C.B. \& Rodrigues, R.R. 2000. Análise estrutural e aspectos do mosaico sucessional de uma floresta semidecídua em Botucatu, SP. Scientia Forestalis 57: 27-43.

Gandolfi, S., Leitão Filho, H.F. \& Bezerra, C.L. 1995. Levantamento florístico e caráter sucessional das espécies arbustivo-arbóreas de uma floresta mesófila semidecídua no município de Guarulhos - SP. Revista Brasileira de Biologia 55: 753-767.

Howe, H.F. \& Smallwood, J. 1982. Ecology of seed dispersal. Annual Review of Ecology and Systematics 13: 201-28.

JICA - Japan International Cooperation Agency. 1990. The study on the disaster prevention and restoration project in Serra do Mar, Cubatão region, State of São Paulo, São Paulo.

Jordão, S.M.S. \& Poggiani F. 2009. O extrativismo predatório de palmito. In: M.I.M.S. Lopes, M. Kirizawa \& M.M.R.F. Melo (eds.). Patrimonio da Reserva Biológica do Alto da Serra de Paranapiacaba: a antiga Estação Biológica Alto da Serra. Instituto de Botânica, São Paulo, pp. 475-489.

Köppen, W. 1948. Climatologia: con un estudio de los climas de la tierra. Fondo de Cultura Económica, México.

Leitão Filho, H.F. 1993. Ecologia da Mata Atlântica em Cubatão. Editora da Universidade Estadual Paulista \& Editora da Universidade Estadual de Campinas. São Paulo \& Campinas.

Lieberman, D., Lieberman, M., Peralta, R. \& Hartshorn, G.S. 1996. Tropical forest structure and composition on a large-scale altitudinal gradient in Costa Rica. Journal of Ecology 84: 137-152.

Liebsch, D., Marques, M.C.M. \& Goldenberg, R. 2008. How long does the Atlantic Rain Forest take to recover after a disturbance? Changes in species composition and ecological features during secondary succession. Biological Conservation 141: 1117-1125.

Losos, E.C. 2004. The structure of Tropical Forests. In: E.C. Losos \& E.G. Leigh (eds.). Tropical forest diversity and dynamism: findings from a large-scale plot netork. The University of Chicago Press, Chicago, pp. 69-78.

Mamede, M.C.H., Cordeiro, I., Rossi, L., Melo, M.M.R.F. \& Oliveira, R.J. 2004. Mata Atlantica In: A.O.V. Marques \& W. Duleba (eds.). Estação Ecológica JuréiaItatins: Ambiente físico, flora e fauna. Holos, Ribeirão Preto, pp. 115-132.

Martins, F.R. 1991. Estrutura de uma floresta mesófila. Editora da Universidade Estadual de Campinas, Campinas.

Meireles, L.D., Shepherd, G.J. \& Kinoshita, L.S. 2008. Variações na composição florística e na estrutura fitossociológica de uma floresta ombrófila densa alto- 
montana na Serra da Mantiqueira, Monte Verde, MG. Revista Brasileira de Botânica 31: 559-574.

Melo, M.M.R.F. \& Mantovani, W. 1994. Composição florística e estrutura de um trecho de mata atlântica de encosta na Ilha do Cardoso (Cananéia, SP, Brasil). Boletim do Instituto de Botânica 9: 107-158.

Melo, M.M.R.F., Oliveira, R.J., Rossi, L., Mamede, M.C.H. \& Cordeiro, I. 2000. Estrutura de um trecho de floresta atlântica de planície na Estação ecológica Juréia-Itatins, Iguape, SP. Hoehnea 27: 299-322.

MISSOURI Botanical Garden's VAST (Vascular Tropicos) nomenclatural database - W3 Tropicos. http://www.tropicos.org (acesso em 02.2010).

Mueller-Dombois, D. \& Ellenberg, H. 1974. Aims and methods of vegetation ecology. Willey and Sons, New York.

Oldeman, R.A.A. 1983. Tropical rain forest, architecture, silvigenesis and diversity. In: S.L. Sutton, T.C. Whitmore \& A.C. Chadwick (eds.). Tropical rain forest ecology an management. Blackwell, Oxford pp. 139-150.

Oliveira Filho, A.T. \& Fontes, M.A.L. 2000. Patterns of Floristic Differentiation among Atlantic Forests in Southeastern Brazil and the Influence of Climate. Biotropica 32: 793-810.

Parthasarathy, N. 1999. Tree diversity and distribution in undisturbed and human-impacted sites of tropical wet evergreen forest in southern Western Ghats, India. Biodiversity and Conservation 8: 1365-1381.

Pielou, E.C. 1975. Ecological diversity. Willey-Interscience, New York.

PMSA. 2005. Atlas do Parque Natural Municipal Nascentes de Paranapiacaba. Desvendando um Novo Parque. Prefeitura de Santo André, Santo André.

PMSA. 2008. Atlas do Parque Natural Municipal Nascentes de Paranapiacaba. Revelando o nosso parque. 2 ed. Prefeitura Municipal de Santo André, Santo André.

Pompéia, S.L. 1997. Sucessão secundária da Mata Atlântica em áreas afetadas pela poluição atmosférica Cubatão, SP. Tese de Doutorado, Universidade de São Paulo, São Paulo.

Pompéia, S.L. 2006. Respostas das plantas nativas brasileiras à poluição. In: W. Larcher (ed.). Ecofisiologia vegetal. Rima Artes e Textos, São Carlos, pp. 439-454.

Porto, M.L., Wildi, O. \& Assunção, A.F. 2008. Análise de gradiente de comunidades vegetais e sua relação com fatores edáficos em um remanescente florestal no sul do Brasil. In: M.L. Porto (ed.). Comunidades Vegetais e Fitossociologia: fundamentos para Avaliação e Manejo de Ecossistemas. Editora da Universidade Fedral do Rio Grande do Sul, Porto Alegre, pp. 162-183.

Richards, P.W. 1952. Estudio de la vegetación tropical. Unasylva 10: 171-175.

Rodrigues, L.A., Carvalho, D.A., Oliveira Filho, A.T. \& Curi, N. 2007. Efeitos de solos e topografia sobre a distribuição de espécies arbóreas em um fragmento de floresta estacional semidecidual, em Luminárias, MG. Revista Árvore 31: 25-35.

Rother, D.C., Rodrigues, R.R. \& Ferreira, M.A.P. 2009. Effects of bamboo stands on seeds rain and seed limitation in a rain forest. Forest Ecology and Management 257: 885-892.

Saldarriaga, J.G. \& Uhl, C. 1991. Recovery of forest vegetation following slash-and-burn agriculture in the upper rio Negro. In: A. Gomez-Pompa, T.C. Whitmore \& M. Hadley (eds.). Tropical rain forest: regeneration and management. Blackwell, New York, pp. 303-312.

Shepherd, G.J. 2006. FITOPAC 1.6.4: Manual do usuário. Universidade Estadual de Campinas. Unicamp, Departamento de Botânica, Campinas.

Silva, A.C., van den Berg, E., Higuchi, P., Oliveira Filho, A.T., Marques, J.J.G.S.M., Appolinário, V., Pifano, D.S., Ogusuku, L.M. \& Nunes, M.H. 2009. Florística e estrutura da comunidade arbórea em fragmentos de floresta aluvial em São Sebastião da Bela Vista, Minas Gerais, Brasil. Revista Brasileira de Botânica 32: 283-297.

Silva, K.E.d., Matos, F.D.A. \& Ferreira, M.M. 2008. Composição florística e fitossociologia de espécies arbóreas do Parque Fenológico da Embrapa Amazônia Ocidental. Acta Amazonica 38: 213-222.

Siqueira, A.S., Araújo, G.M. \& Schiavini, I. 2009. Estrutura do componente arbóreo e características edáficas de dois fragmentos de floresta estacional decidual no vale do rio Araguari, MG, Brasil. Acta Botanica Brasilica 23: 10-21.

Solórzano, A., Oliveira, R.R. \& Guedes-Bruni, R.R. 2005. História ambiental e estrutura de uma floresta urbana. In: R.R. Oliveira (ed.). As marcas do homem na floresta: História ambiental de um trecho de mata atlântica. Editora PUC-Rio, Rio de Janeiro, pp. 87-118.

Spiegel, M.R. 1976. Estatística. Mac-Graw-Hill, São Paulo. Sugiyama, M., Rebelo, C.F., Catharino, E.L.M. \& Vuono, Y.S.D. 2009. Aspectos da estrutura e da diversidade da floresta. In: M.I.M.S. Lopes, M. Kirizawa \& M.M.R.F. Melo (eds.). Patrimônio da Reserva Biológica do Alto da Serra de Paranapiacaba: a antiga Estação Biológica Alto da Serra. Instituto de Botanica, São Paulo, pp. 119136.

Swaine, M.D. \& Whitmore, T.C. 1988. On the definition of ecological species groups in tropical rain forests. Vegetatio 75: 81-86.

Tabarelli, M. \& Mantovani, W. 1999. A regeneração de uma floresta tropical montana após corte e queima (São Paulo - Brasil). Revista Brasileira de Botânica 59: 239-250.

Tabarelli, M., Mantovani, W. \& Peres, C.A. 1999. Effects of habitat fragmentation on plant guild structure in the montane Atlantic forest of southeastern Brazil. Biological Conservation 91: 119-127. 
Torquebiau, E.F. 1986. Mosaic patterns in dipteriocarp rainforest in Indonesia and their implications for pratical forestry. Journal of Tropical Ecology 2: 301-325.

Van der Pijl, L. 1972. Principles of dispersal in higher plants. 2 ed. Springer-Verlag, New York.

Veloso, H.P., Rangel Filho, A.L. \& Lima, J.C.A. 1991. Classificação da vegetação brasileira, adaptada a um sistema universal. IBGE, Rio de Janeiro.

Watt, A.S. 1947. Pattern and process in the plant community. Journal of Ecology 35: 1-22.

Whitmore, T.C. 1975. Tropical rain forests of the far East. Clarendon Press, Oxford.

Whitmore, T.C. 1978. Gaps in the forest canopy. In: P.B.
Tomlinson \& M.H. Zimmerman (eds.). Tropical trees as living systems. Cambridge University Press, Cambridge, pp. 639-655.

Whitmore, T.C. 1982. On pattern and process in forests. In: E.I. Newman (ed.). The plant community as a working mechanism. Blackwell Scientific, Oxford, pp. 45-59.

Whitmore, T.C. 1989. Canopy gaps and two major groups of forest trees. Ecology 70: 536-538.

Whitmore, T.C. 1990. An introduction to tropical rain forest. Oxford University Press, New York.

Yamamoto, L.F., Kinoshita, L.S. \& Martins, F.R. 2005. Florística dos componentes arbóreo e arbustivo de um trcho da Floresta Estacional Semidecídua Montana, município de Pedreira, estado de São Paulo. Revista Brasileira de Botânica 28: 191-202. 